Rhode Island College

Digital Commons @ RIC

$1-1-2010$

\title{
Napping to Reduce Sleepiness, Fatigue and Improve Reasoning for Nursing Shift Workers
}

Cheryl Beth Bourdony

Rhode Island College

Follow this and additional works at: https://digitalcommons.ric.edu/etd

Part of the Public Health and Community Nursing Commons

\section{Recommended Citation}

Bourdony, Cheryl Beth, "Napping to Reduce Sleepiness, Fatigue and Improve Reasoning for Nursing Shift Workers" (2010). Master's Theses, Dissertations, Graduate Research and Major Papers Overview. 209. https://digitalcommons.ric.edu/etd/209

This Major Paper is brought to you for free and open access by the Master's Theses, Dissertations, Graduate Research and Major Papers at Digital Commons @ RIC. It has been accepted for inclusion in Master's Theses, Dissertations, Graduate Research and Major Papers Overview by an authorized administrator of Digital Commons @ RIC. For more information, please contact digitalcommons@ric.edu. 


\section{NAPPING TO REDUCE SLEEPINESS, FATIGUE AND IMPROVE REASONING FOR \\ NURSING SHIFT WORKERS}

A Major Paper Presented

By

Cheryl Beth Bourdony

Approved:

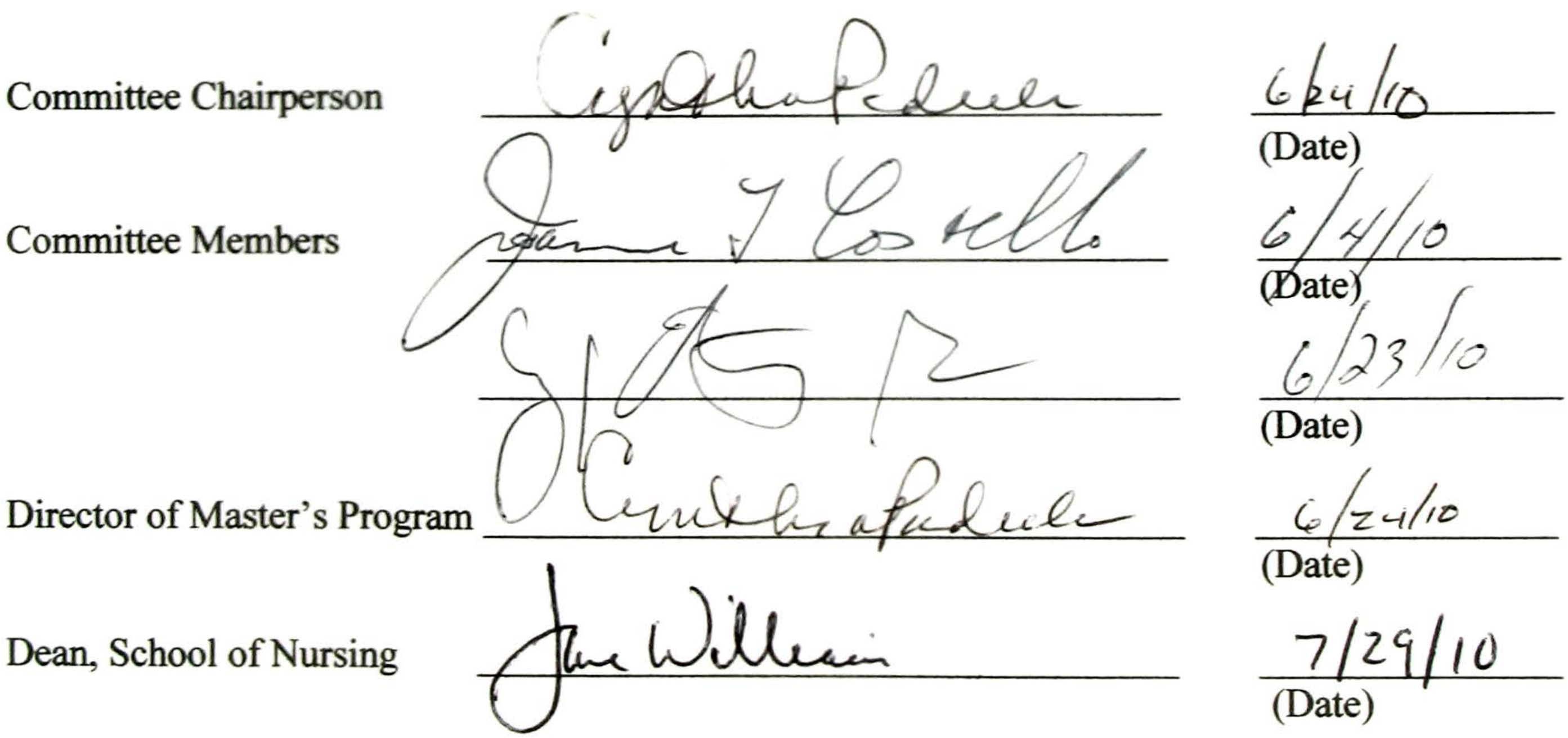


NAPPING TO REDUCE SLEEPINESS,

FATIGUE, AND IMPROVE REASONING FOR NURSING SHIFT WORKERS

by

Cheryl Beth Bourdony

\begin{abstract}
A Major Paper Submitted in Partial Fulfillment
of the Requirement for the Degree of

Master of Science in Nursing
\end{abstract}

in

The School of Nursing

Rhode Island College

2010 


\begin{abstract}
Shift work outside the normal working hours of 6 a.m. to 6 p.m. is a requirement in acute and chronic care facilities that provide nursing care on a 24 -hour basis. Slightly more than $30 \%$ of full-time health care workers are shift workers. Shift work sleep disorder, defined as a primary complaint of insomnia and excessive sleepiness, has been diagnosed in almost ten $\%$ of shift workers. The excessive sleepiness and fatigue nursing shift workers experience often lead to performance impairment and diminished attentiveness that may affect job productivity and patient safety. Napping is the most natural countermeasure against sleepiness. This quasiexperimental study was performed to determine whether a 20 minute nap during the night shift could reduce sleepiness and fatigue and improve cognitive functioning among nursing shift workers in an acute care setting. Ten study participants were randomly assigned to participate in both the control (no nap) and the intervention (nap) within the two week study. Self-testing of fatigue and sleepiness, and a timed reaction test programmed into a personal digital assistant (PDA) were performed throughout the two shifts. Results showed a trend toward a reduction in sleepiness and fatigue were reduced when nursing staff took a 20 minute nap during shift work, that was sustained through the remainder of the shift. The Advanced Practice Nurse is critical to advancing napping for shift workers because she/he can interpret, evaluate, and participate in research, create evidence-based policy, and collaborate with key stakeholders.
\end{abstract}




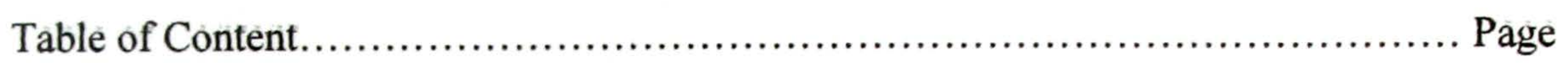

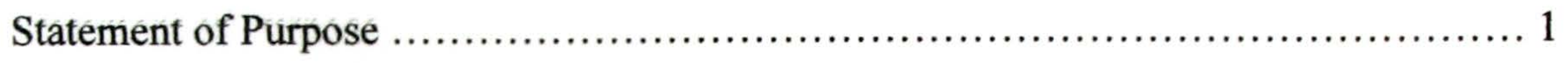

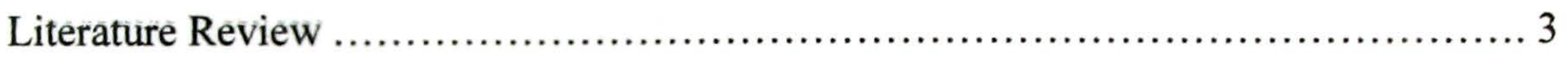

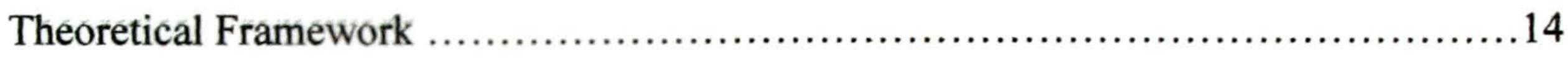

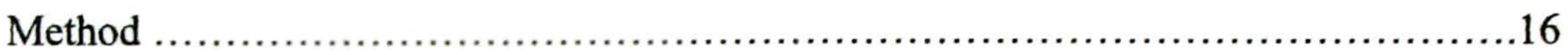

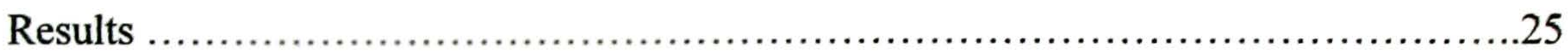

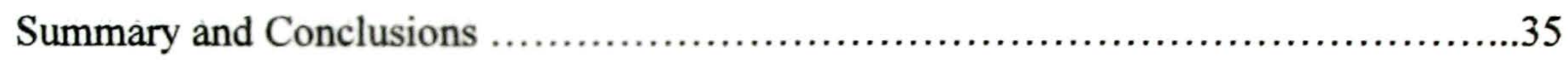

Recommendations and Implications for Advanced Practice Nursing..................40

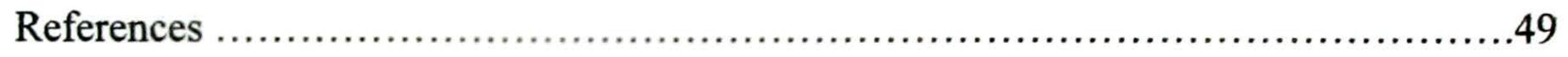

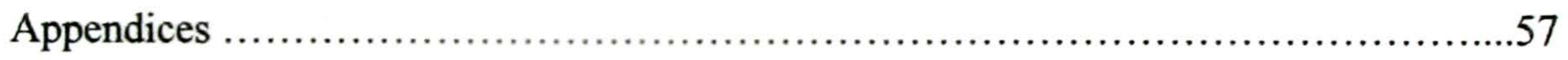


Napping to Reduce Sleepiness,

Fatigue, and Improve Reasoning for Nursing Shift Workers

Statement of the Problem

The Institute of Medicine [IOM] (1999) report To Err is Human: Building a Better Health System concluded that as many as 100,000 patient deaths per year may be due to medical errors that could have been prevented. The 2004 IOM report, Keeping Patients Safe: Transforming the Work Environment of Nurses, acknowledged the critical róle nurses play in patient safety. Sleepiness and fatigue experienced by nurses, especially shift workers, can adversely affect patient safety. Sleepiness refers to the tendency to fall asleep (Rogers, 2008). Pigeon, Seteia and Ferguson (2003) defined fatigue as weariness, weakness and depleted energy. The effects of fatigue include delayed réaction times, delayed responses, delayed thinking, diminished memory, failure to respond at the appropriate time, impaired efficiency, and provision of false responsés (Peate, 2007). Seki and Yamazaki (2006) reported shift work fatigue to be a more common factor leading to medical accidents than staffing shortage.

Shift work outside the normal working hours of 6 a.m. to 6 p.m. is a requirement in acute and chronic care facilities that provide nursing care on a 24-hour basis (Berger \& Hobbs, 2006; Blachowicz \& Letizia, 2006). Balancing family and social demands along with shift work schedules can lead to reduced or disrupted sleep and prolonged wakefulness (Berger \& Hobbs, 2006; Hughes \& Stone, 2004; Kunert, King, \& Kolkhorst, 2007). Daytime sleep sessions are often shorter and provide less restorative value than a full night's sleep (Takeyama, Kubo, \& Itani, 2005). Rouch, Wild, Ansiau, and Marquie 
(2005) concluded that cognitive functioning tended to be impaired by a long-time exposure to shift work. Excessive fatigue and its risks are highly preventable when the causes are identified and alleviated. Napping during shift work has been shown to be extremely effective at eliminating fatigue-related accidents and injuries (Humm, 2008; Kunert et al., 2007; National Sleep Foundation, 2008; Owens, 2007; Schwartz \& Roth, 2006). To Err is Human (1999) concluded that health care organizations must include well understood safety principles, such as designing jobs and working conditions for safety, to ensure safe practice at the delivery level. The National Sleep Foundation (2008) recommended that organizations develop policies that support workplace napping by providing dedicated sleep areas to improve alertness, judgment, safety and productivity. 


\section{Literature Review}

A search on CINAHL and MEDLINE databases was conducted using keywords nap, napping, sleep, shift work, shift workers, sleep inertia, nursing, healthcare, and shift work sleep disorder for the literature review.

Sleep Physiology

Sleep and wakefulness are fundamental neurobiological states that are a universal need of all higher life forms including humans (IOM, 2006; Peate, 2007). The sleep homeostatic and circadian systems act to coordinate most physiologic and behavioral systems. The circadian system may be viewed as a system that maintains wakefulness, and the homeostatic sleep system promotes sleep need and provides a drive for sleep (IOM, 2006; Millman, 2005). These two systems work together or in opposition, modulating physical activity and food consumption, and regulating body temperature, heart rate, muscle tone, and secretion of the hormones melatonin and cortisol (IOM, 2006; Millman, 2005). The need for sleep accumulates across the day, peaks at bed time and dissipates through the night. The circadian cycle builds across the day, serving to counteract the need for sleep and promote wakefulness and alertness. In general, individuals need about one hour of sleep for every two hours they are awake, or eight to nine hours a night (Peate, 2007).

The central circadian pacemaker, or biological clock, located in the suprachiasmatic nuclei (SCN) of the anterior hypothalamus, is synchronized to the 24-hour day through external environmental time cues called zeitgebers (Millman, 2005; Peate, 2007). The strongest of these zeitgebers is exposure to the light/dark cycle via nerve cells in the 
retina that act as brightness detectors, which can reset the $\mathrm{SCN}$ on a daily basis (IOM, 2006; Millman, 2005). As a result, alertness is usually lowest in the early morning and increasés into the late afternoon or evening until declining at bedtime when growing sleepiness opposes wakefulness and sleep occurs (Millman, 2007).

There are two types of sleep, non-rapid eye-movement (NREM) sleép and rapid éyemovement (REM) sleep. NREM sleep is divided into stages one, two, three and four, representing a continuum of relative depth. NREM constitutes about 75 to 80 percent of total time spent in sleep, and REM sleep constitutes the remaining 25 to 20 percent (IOM, 2006). Over the course of a period of sleep, NREM and REM sleep alternate four to six cycles of about 90 to 110 minutes (IOM, 2006; Lindsey, 2007). The function of alterations between the two types of sleep is not yet understood, but irregular cycling and/or absent sleep stages are associated with sleep disorders (IOM, 2006).

\section{Sleep Disorders}

It is estimated that 50 to 70 million Americans chronically suffer from a disorder of sleep and wakefulness, hindering daily functioning and adversely affecting health and longevity (IOM, 2006). Sleep disorders affect infants, children, adolescents, young adults, adults, and the elderly. Among adolescents and young adults, excessive sleepiness can have a profound negative effect on school performance, cognitive function, and mood and has been associated with other serious consequences such as increased incidence of automobile accidents (Millman, 2005). Many medical disorders can impair sleep quality and can, in turn, be adversely affected by poor sleep (National Sleep Disorders Research Plan, 2003). The cumulative long-term effects of sleep 
deprivation and sleep disorders have been associated with a wide range of health consequences including an increased risk of hypertension, diabetes, obesity, depression, heart attack, stroke (IOM, 2006), menstrual cycle disturbances (Rouch et al., 2005), peptic ulcer disease, and coronary heart disease (Basner, 2005; Schwartz \& Roth, 2006).

Compared to healthy individuals, those suffering from sleep loss and sleep disorders are less productive, show reduced quality performance, demonstrate an increased health care utilization, and have an increased likelihood of injury to themselves and others (Berger \& Hobbs, 2006; Blachowicz \& Letizia, 2006; IOM, 2006; Kunert et al., 2007; Monk, 2007). The most common sleep conditions include sleep-disordered breathing, insomnia, narcolepsy, restless leg syndrome, parasomnias, sleep-related psychiatric disordèrs, sleep-rèlated neurological disorders, sleep-related medical disorders, circadian rhythm sleep disorders, and sleep loss (IOM, 2006).

Sleep lōss in adults is defined as sleep of shorter duration than the average basal need of seven to eight hours per night (IOM, 2006). The main symptom of sleep loss is fatigue, but other symptoms include depressed mood, irritability, reduced performance, poor memory or concentration, and decreased mental agility (Hughes and Stone, 2004; IOM, 2006). Fatigue is defined in the National Sleep Disorders Research Plan (USDHHS, 2003) as "a reduced capacity for cognitive performance due to time-on-task, inadequate sleep, adverse circadian timing, or the interaction of these factors" (p. 63). The causes of sleep loss fall under two major somewhat overlapping categories: sleep disorders and lifestyle/occupational (IOM, 2006). An occupational cause of sleep loss is shift work. 


\section{Shift Work}

Almost 20 percent of workers in industrialized nations participate in shift work (Basner, 2005; IOM, 2006). The number of persons in the United States (US) leaving home to travel to work between 12:00 a.m. and 7:00 a.m. has increased from 17.6\% in 1990 to $19.7 \%$ in 2000 (Reschovsky, 2004). Occupations affected by shift work include the military, food services, transportation, manufacturing, police, firefighters, security personnel, and health care providers (Blachowicz \& Letizia, 2006). Folkard, Lombardi, and Tucker (2005) conducted a review of epidemiological studies on shift work and safety to determine the relative risk of accidents or injuries associated with shift work. One consistent trend identified in the risk of incidents is related to the number of successive night shifts worked. On average, the risk of an incident was about $6 \%$ on the second night, $17 \%$ on the third night, and $36 \%$ higher on the fourth night than on the first night (Dräkè êt al., 2004).

Åkerstedt (2006) stated that shift workers, particularly those working night shift, complained about sleepiness and disturbed sleep, reporting experiences of involuntary sleep during night work. These symptoms are likely due to the fact that shift workers' sleep-wake cycle are out of phase and often in direct opposition to their endogenous circadian rhythms (Drake, Roehrs, Richardson, Walsh, \& Roth, 2004).

\section{Shift Work Sleep Disorder}

Shift work sleep disorder (SWSD), defined as a primary complaint of insomnia or excessive sleepiness temporally associated with a work period that occurs during the habitual sleep phase, has been diagnosed in as many as $10 \%$ of shift workers (Basner, 
2005; Drake et al., 2004). The prevalence of insomnia or excessive sleepiness is $32 \%$ and $26 \%$ in night and rotating shift workers respectively (Drake et al., 2004). A common complaint among night shift workers is disrupted and nonrefreshing daytime sleep and that those sleep difficulties become more severe with increasing age (Schweitzer, Randazzo, Stone, Erman, \& Walsh, 2006). Fatigue associated with shift work can adversely affect public health and safety due to oil spills, vehicular accidents, railroad and commuter train accidents, aviation accidents and near misses, power plant mishaps, and medical errors (Monk, 2007; National Sleep Disorders Reseäch Plan, 2003).

Slightly more than $30 \%$ of full-time health care workers are shift workers, with almost $11 \%$ of them working evening shifts ( 3 p.m. to 11 p.m.), $9 \%$ working night shifts (11p.m. to 7 a.m.), $3 \%$ working rotating shifts, and the remaining working split shifts and other arranged shifts (Hughes \& Stone, 2004). Schwartz and Roth (2006) reported that excessive sleepiness and fatigue that shift workers experienced often led to performance impairment and diminished attentiveness that may affect job productivity and patient safety. Safety is impaired when individuals struggle to stay awake during the second half of a shift, especially at night (Berger \& Hobbs, 2006; Hughes \& Stone, 2004).

\section{Shift Work Sleep Disorder Interventions}

Interventions that have been studied to relieve or decrease sleepiness during shift work include reentrainment, or training the body to be the most alert during the evening hours and into the night and sleeping during the day (Berger \& Hobbs, 2006; Blachowicz \& Letizia, 2006; Owens, 2007; Peate, 2007), pharmaceuticals and caffeine (Åkerstedt, 
2006; Blachowicz \& Letizia, 2006; Kunert et al., 2007; Schwartz \& Roth, 2006), light exposure (Åkerstedt, 2006; Peate, 2007; Schwartz \& Roth, 2006), exercise (Åkerstedt, 2006; Berger \& Hobbs, 2006; Blachowicz \& Letizia, 2006; Owens, 2007; Schwartz \& Roth, 2006), and naps (Akerstedt, 2006; Bonneford, Muzet, Winter-Dill et al., 2001; Hughes \& Stone, 2004; Kunert et al., 2007; Owens, 2007; Purnell, Fèyer, \& Herbison, 2002; Sallinen, Härmä, Åkerstedt, Rosa, \& Outilillqvist, 1998; Schwartz \& Roth, 2006; Takahashi, Arito \& Fukuda, 1999). Napping represents the most natural countermeasure against sleepiness (Akerstedt, 2006). The National Guideline Clearinghouse (2008) stated that the standard for treatment of SWSD includes planned napping before or during the night shift to improve alertness and performance among night shift workers. The National Sleep Disorders Research Plan (2003) recommended that research is needed to establish the biological benefits for brain function, performance, and safety of nap sleep interventions as a fatigue management strategy in the workplace.

Owens (2007) recommended that 'maintenance' or on-the-job naps may improve performance in shift workers, but cautioned that the optimal timing and duration of napps so as to be effective, must be considered when conducting research on napping as a countermeasure to fatigue. Tietzel and Lack (2002) examined the effects of brief and ultra-brief naps on fatigue by comparing no nap and 30 second nap, 90 second nap, and 10 minute nap. The results showed that the no nap and ultra-brief naps conditions had no effect on fatigue and that the 10 minute nap reduced fatigue 35 minutes following the nap. Hayashi, Motoyoshi, and Hori (2005) confirmed that short naps (less than 30 minutes) with a minimum of three minutes of stage two sleep had recuperative effects on 
alertness and performance as demonstrated by subjective mood and performance on visual detection and a symbol-digital substitution task. The study designs of both Tietzel and Lack (2002) and Hayashi et al. (2005) were restricted to the study of a daytime nap following restricted nocturnal sleep, but the implications of both studies can be applied to shift work. Hayashi et al. concluded that the maximum recuperative benefit of a daytime nap is achieved when it is taken when afternoon sleepiness is greatest. Therefore the benefits of a nap during shift work should be taken when sleepiness is greatest, between 1:00 a.m. and 4:00 a.m.

Hayashi, Chikazawa, and Hori (2004) compared a 20 minute nap with a 20 minute rest as an intervention for fatigue recovery and fatigue prevention during visual displáy terminal (VDT) work. The participants $(n=10)$ performed a memory search task for two hours and rated their mood every ten minutes. The participants took a 20 minute nap or a 20 minute rest (the average length of a shift break in nursing) one hour after VDT work, followed by another one hour of VDT work. The results showed that a 20 minute rest temporarily restored subjective sleepiness, but it deteriorated during the additional one hour of work. A 20 minute nap, however, maintained subjective alertness and performance level at a higher level and mental fatigue at a lower level for the additional hour of work. Hayashi et al. postured that the findings may provide a new work/rest strategy.

In an experimental laboratory study of rotating shift-workers $(n=14)$, Sallinen et al. (1998) initiated either a 30 minute or a 50 minute nap at either 1:50 am or 4:40 am, with a control group of no nap. Performance, physiological sleepiness, and subjective 
sleepiness were measured in addition to answers provided to three questions after daytime sleep about sleep quality. Sallinen et al. found that those who napped during the night shift compared with those who did not nap experienced less of an increase in reaction time, and that alertness improved to a certain extent no matter the length or scheduled time of the nap.

Kubo, Takeyama, Matsumoto et al. (2005) studied the effects of nocturnal nap length and timing on early morning performance. The experiment was composed of five nap conditions: naps taken at midnight for 60 and 120 minutes; naps taken at 4:00am for 60 and 120 minutes; and no nap. Participants $(\mathrm{n}=12)$ completed all nap conditions in a counterbalanced order during laboratory simulated night shifts that began at 10:00 pm and ended at 8:00 am. Participants completed a performance test battery thăt consisisted of a modified version of psychomotor vigilance test (PVT), a logical reasoning test, and a visual analogue scale. Both 60 and 120 minute naps in the latter part of the night produced a better sleep quality.

Purnell, Feyer, and Herbison (2002) conducted a counterbalanced crossover design study of male aircraft maintenance engineers $(n=24)$ working a forward rotating 12-hour shift pattern over two weeks. Subjects took a 20 minute nap between 1:00 am and 3:00 am during the two night shifts. Controls were not allowed to sleep. Participants were administered a short questionnaire at the start and end of each shift to collect data about the sleep obtained during their nap and their level of sleepiness driving to and from work. In addition, a battery of performance tests that consisted of three subjective fatigue rating scales, a two minute simple reaction time task, and a ten minute PVT was completed via 
computer. Results found that a single 20 minute nap taken at 3:00 am (during normal break time) significantly improved performance on a vigilance task.

Bonnefond et al. (2001) performed a qualitative cohort study of the long term effects of implementing a short nap during night shifts. Male power plant shift workers $(n=12)$ were followed over a year while completing daily questionnaires concerning: schedule and quality of last main sleep; use of a nap during the daytime; mood during work and outside work; use of a nap during the night shift including time spent asleep and quality of awakening. The results showed that a maximum of one hour nap during the shift between 11:30 pm and 3:30 am led to less fatigue and sleepiness and a gain in energy, counteracting the low level of vigilance that normally occurs during the second half of the shift.

Smith-Coggins, Howard, and Mac et al. (2006) conducted a randomized, controlled intervention study with physicians and nurses working 12 hour night shifts at a university emergency department that introduced napping as an intervention to improve cognition and psychomotor performance and ability to drive home. All participants $(n=49)$ were studied on the second and third night of a three-block assignment. The second night subjects worked their shift in the usual fashion. On the third night shift, subjects were randomized into nap or no-nap groups at 11 p.m. The nap group took a 40 minute nap at 3 a.m. Performance tests (PVT, Probe Recall Memory Task, CathSim intravenous insertion virtual simulation, and Profile of Mood States) were administered to both groups, before, during, and after night shifts. The results showed that a nap at 3 a.m. 
improved performance at 7:30 a.m. compared to a no-nap condition. An additional finding was that immediately after the nap, memory temporarily worsened.

Sleep inertia, the performance impairment that occurs immediately after awakening, has important implications for occupations in which personnel are expected to perform immediately upon awakening and must be considered when designing a nap intervention (Bruck \& Pisani, 1999; Wertz, Ronda, Czeisler, \& Wright, 2006). Takkahashi, Arito, and Fukuda (1999) found that among nurses ( $\mathrm{n}=20$ ) working a two shift system (an eight hour day shift and a 16 hour night shift) who took a two hour nap between 10:00 pm and 4:00 am, post-nap fatigue lasted longer as the nap length increased beyond 1.5 hours.

Wertz et al. (2006) compared the effects of sleep inertia and sleep deprivation on cognition. Participants $(n=9)$ were admitted to an inpatient laboratory for six days with eight hours of sleep per night followed by 26 hours of monitored sleep deprivation in a laboratory simulation. Cognitive function was examined immediately upon wakening on the seventh day and during the sleep deprivation by use of cognitive operations using short-term memory, counting skills, speed of cognitive processing, and number fact and lexical retrieval. Findings showed that cognitive performance was worse immediately upon waking than during subsequent sleep deprivation. A nap intervention must include time for sleep inertia to dissipitate before returning to duty.

Creek (2004) conducted a descriptive pilot study to determine the feasibility of napping for nurses working 12 hour night shifts in an acute care setting. Participants $(n=7)$ took a 30 minute nap worked into a one hour break between 1:00 and 3:00 a.m. Sleepiness and fatigue was self-assessed every two hours as well as immediately before 
and 15 to 20 minutes after the nap. Cognitive function was assessed by Digit-Span Test, Stroop Task, and Long Term Memory Test immediately before and 15 to 20 minutes after the nap. Creek concluded that sleepiness and fatigue decreased following the nap and then increased to pre-nap levels by the end of shift. Cognitive function showed no difference between pre- and post-nap testing. A limit to this study was lack of a control group (no nap) to determine whether post-nap data would have been higher than control post-nap data. The data supports further research using a control group.

The literature shows that field testing of napping among nursing shift workers in the acute care setting is lacking. Growing bodies of literature supports napping among nurses, but those studies are limited to nurses who work non-traditional hours, i.e. 12 hours shifts and/or with a high acuity patient population, i.e. emergency departments and intensive care units. The purpose of this study was to pilot napping among nurses and nurse's aides working either 8 hour or 12 hour shifts on inpatient units in the acute care setting. 


\section{Theoretical Framework}

The Theory of Planned Behavior (TpB; Ajzen, 2006; Figure 1) guided the development of this study.

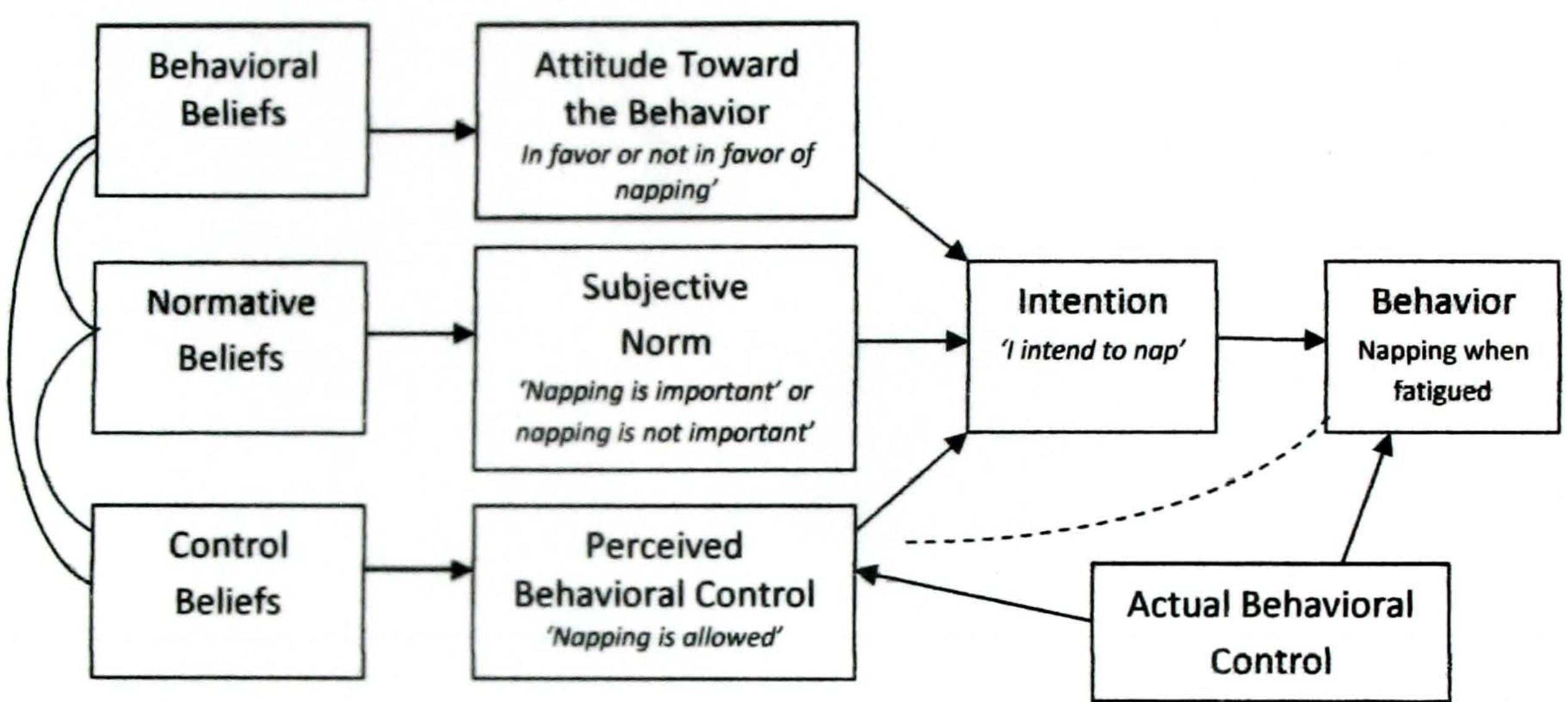

Figure 1. Diagram of Theory of Planned Behavior applied to napping

The $\mathrm{TpB}$ is guided by three considerations: beliefs about the likely outcomes of the behavior and the evaluation of these outcomes (behavioral beliefs); beliefs about the normative expectations of others and motivation to comply with these expectations (normative beliefs); and belief about the presence of factors that may facilitate or impede performing the behavior and the perceived power of these factors (control beliefs) (Ajzen, 2006). Behavioral intention comes from the combination of attitude toward the behavior (napping will or will not decrease fatigue during the night shift), subjective norm (napping during the shift will decrease fatigue and improve patient outcomes), and perception of behavioral control (allowed to nap when fatigued). By changing one or 
more of the behavioral beliefs, the chance of a person intending to participate in a particular desired behavior increases and the chance of a person routinely napping when fatigued increases.

Interventions following the $\mathrm{TpB}$ are designed to change behavior by affecting one or more of its determinants: attitudes, subjective norms, or perception of behavioral control. Changes in these factors should produce changes in behavioral intention, and if there is adequate control over the behavior, the intention becomes the behavior sought.

Azjen (2006) concluded that if there is opportunity for change in two or all three predictors, then the relative weight of a given factor should be considered in designing the intervention. Azjen noted that the greater the relative weight of a factor, the more likely it is that changing that factor will influence intention and behavior. The goal of this study is to contribute to the literature that is beginning to emerge which recommends nurses' napping as an accepted practice by demonstrating its positive effects on patient outcomes. The literature has shown that napping decreases fatigue and improves cognitive function, therefore increasing patient safety (the subjective norm). Yet napping is not an accepted practice among healthcare facilities in this area (perceived behavioral control). While many nurses experience fatigue and its effects during shift work, the benefits of a nap on patient safety may or may not be known to them. By focusing this study on the subjective norm (showing that napping can improve patient outcomes), it is anticipated that attitude toward the behavior will become more favorable (napping will decrease fatigue during the night shift), thus hopefully affecting intentions and behavior (sanctioned napping during shift work). 


\section{Method}

\section{Research Question and Variables}

The research question was: What impact would a 20 minute nap during scheduled break times for night shift nurses and nurses' aides on an acute care unit have on sleepiness, fatigue, and cognitive function? The independent variable was a nap during scheduled break time in a designated area designed for sleep. The dependent variable was reduction in sleepiness and fatigue and improvement in cognition as measured by the Stanford Sleepiness Scale (SSS), Fatigue Assessment Scale (FAS), and Psychomotor Vigilance Testing (PVT).

Confounding variables included age, gender, educational preparation, reentrainment to night shift, home demands (including number of children and ages, school obligations, and social obligations), predisposing conditions identified with sleep disorders, selfperception of napping in the work place, and organizational support for napping.

\section{Research Design}

The design was a crossover, quasi-experimental study. Each study participant was randomly assigned to participate in both the control (no nap) and the intervention (nap) within the two week study. Review and approval of the research plan was completed by the Institutional Review Board of the study facility and Rhode Island College before initiating the study.

\section{Sample and Sampling Plan}

All registered nurses, licensed practical nurses, and certified nurse's aides working either an eight or twelve hour shift between the hours of 7:00 pm and 7:00 am on the 
three identified units were invited by a study facility and Rhode Island College IRB approved letter (Appendix A) to participate in the study. Names and addresses were obtained through the Nursing Department. The researcher's telephone number and email address were included in the invitation letter for potential participants to call with questions or interest in participating.

Following a failed mailing attempt to recruit study participants, the researcher conducted a face to face informational session on each of the identified units between 2 a.m. and 4 a.m. on two separate nights in order to reach all eligible participants. Thirty eligible participants attended the sessions, with 11 participants agreeing to participate in the study. Exclusion criteria included a known sleep disorder or taking any medication that affects sleep. No interested participants were excluded based on the criteria. Each participant gave written consent and received a copy of their signed consent form (Appendix B). Original signed consent forms remain in the possession of the researcher in a secured location.

In order to maintain confidentiality, study participants were assigned a random number for identification. A list of random numbers were generated by http://www.random.org/sequences/ with the smallest value equal to one and the largest value equal to one hundred. Each sleep journal (Appendix C) and demographic sheet (Appendix D) was given matching random numbers beginning with the first number in the list and ending with the eleventh. Each participant was then randomly given a sleep journal and demographic sheet once a signed consent form was returned to the researcher. 
The random journal number was also used by the participant to identify completed selftesting scales and reaction time test for purposes of comparing data.

\section{Setting}

The study was conducted over two weeks on three inpatient units at a local acute care hospital: one rehabilitation unit and two medical surgical units. A dedicated quiet area for napping was identified on each unit and provided with a mobile folding cart, bed linens, dim lighting, an alarm clock, and an optional sleep mask. Identified areas included the staff lounge, family room, and the family waiting room.

\section{Measurements}

Demographic information collected from each study participant included age, sex, title, education, length of career, length of employment, length of shift work, and shift demographics (length, frequency, and rotation). Medical history included having a known sleeping disorder (which disorder and medication use for the disorder), smoking and caffeine use.

Each participant completed a battery of tests which included self-testing of fatigue and sleepiness, and a timed reaction test programmed into a personal digital assistant (PDA), the Palm TXO. Fatigue was measured using the Fatigue Assessment Scale (FAS; Michielsen et al., 2004) (Appendix E). The FAS consists of ten statements which produce a measure of physical and mental fatigue using a Likert scale ranging from (1) never to (5) always. Michielson, De Vries, and Van Heck (2003) tested the FAS for its psychometric qualities, internal consistency, validity, and reliability and concluded that the FAS had good internal consistency reliability $(0.90)$ and validity, and they provided 
strong evidence for its unidimensional conceptualization. Diverging validity was supported in that fatigue and depression were related but distinct constructs (Michielson et al., 2003). De Vries, Michielsen, and Van Heck (2003) concluded that the FAS is an acceptable tool for measuring fatigue among the working population. The FAS is an appropriate tool for this study given its brevity and ease of administration.

The Stanford Sleepiness Scale (SSS) (Hoddes, Dement, \& Zarcone, 1972; Appendix F), a self-assessed rating of alertness, was used by study participants to measure sleepiness. Participants were asked to choose a corresponding number that best described their level of sleepiness at that time, ranging from (1) 'feeling active, vital, alert, or wide awake' to (7) 'no longer fighting sleep, sleep onset soon; having dream-like thoughts'. Hoddes, Dement, \& Zarcone (1972) showed that the reliability of the scale yielded a correlation of $r=.88$. Herscovitch and Broughton (1981) found that the SSS is sensitive to deficits in alertness following partial sleep deprivation.

Cognitive function was tested using the Walter Reed Psychomotor Vigilance Task (PVT) software (Thorne, Johnson, Redmond, Sing, \& Belensky, 2005). The PVT wass developed as a neurocognitive test of behavioral alertness to track changes induced by interaction of the homeostatic drive for sleep and endogenous circadian pacemaker (Dorriann, Rogers, Dinges, 2005). It is a widely accepted measure of neurobehavioral performance when assessing the functional consequences of sleep loss, shift work, and fatigue (Dorriann, Rogers, \& Dinges, 2005; Lamond, Dawson, \& Roach, 2005; Lamond et al., 2008). Dorriann, Rogers, \& Dinges (2005) found that interclass correlation coefficients indicated maximal reliablility for both the number of PVT performance 
lapses and median response times. This study employed the Walter-Reed palm-held PVT software, a field-portable reaction timed (RT) test that was designed to emulate the PVT192, a bulky, specialized, expensive piece of machinery widely used in laboratory and field sleep studies (Lamond et al., 2008). The PVT was loaded onto a personal digital assistant (PDA) so that multiple participants could use the same device. The PDA-PVT is easily performed and is minimally affected by aptitude (Lamond et al.). The participant initiated the test when a visual stimulus (a black bull's eye) appeared on the screen, and responded by pressing a specific button on the PDA. When the test session ended, a brief message indicating reaction time in milliseconds was presented, and the device turned itself off. Validity of PVT of less than 10 minutes was tested by Loh et al. (2004) and was found to be a valid measure of the effects of sleep loss at 5 minutes. This finding is useful in providing an alternative to the 10 minute PDA-PVT when minimal interference to work and the work environment and repeated testing is required. For the purpose of this study, a 5 minute RT test was chosen to assure testing compliance by participants when bundled with the SSS and FAS self-testing multiple times during the shift. Yang, Lin, and Spielman (2004) reported that the SSS has moderate to high correlations ( $r$ value $=.47$ to .70 ) with performance on cognitive tasks.

Each study participant was instructed to keep a sleep journal (Appendix C) provided by the researcher for fourteen days to record sleep quality as defined by the Sleep Quality Index (Harvey, Stinson, Whitaker, Moskovitz, \& Virk, 2008). This included: the time the participant went to bed, sleep onset latency (how long it takes to fall asleep); wake after sleep onset; time of awakening; time spent lying awake before getting up; total sleep 
time; and a rating of overall sleep quality. Participants marked each page in the journal to indicate which days they worked (W), napped $(\mathrm{N})$ or tested $(\mathrm{T})$. It was hoped that the journals would provide data that could explain higher or lower reported levels of sleepiness and fatigue; and slower or faster reaction times correlated to daytime sleep routines and habits.

Following the randomized nap, participants recorded the same sleep quality data in their journal on a dedicated 'nap at work' page. Journals were maintained by the participants and returned to the researcher at the end of the two week study period by inter-office mail or in person. Nine journals were returned. The only journal not returned was due to loss by the participant. However, that participant was able to complete a 'nap at work' page at the end of the study to be included in the data.

\section{Procedures}

The shift ( 8 hour or 12 hour) and number of shifts each participant was scheduled to work during the two week study was determined by reviewing each unit's staffing schedule. The least shifts worked within the two weeks by any participants was two and the most was eight, and no person worked more than four consecutive days.

The study began the third night following the first informational session. The delay in starting the study was so that the researcher, a day shift worker, could develop a daytime sleep routine in order to carry out the study in person. While the study was carried out over 12 days, each participant was asked to make daily entries into their sleep journals for 14 days whether they were scheduled to work or not, beginning with the first night that they received a journal. 
Each participant was handed an assignment envelope by the researcher at the beginning of each of their scheduled shifts during the 12 day study. The number of personalized envelopes created for each participant was based on the number of shifts scheduled to work. Envelope assignments were either 'no nap, but complete the testing', 'you're going to take a nap tonight', or 'no nap/ no testing'. The number of 'no nap/no testing' assignments for each participant matched the number of scheduled shifts beyond the two shifts needed to complete the control and the intervention. Random ordering of the assignments was created at http://www.random.org/sequences/ based on the number of shifts each participant was scheduled to work during the study. Within each participant's randomized list, the number 'one' represented the intervention (nap) and the number 'two' represented the control (no nap but testing). The remaining numbers in the list automatically became a no nap/ no test assignment.

However, in the event that a participant was ill or floated off a unit, the randomization list was reconfigured to the change. One participant who was scheduled to work eight nights was only eligible for five nights because of re-assignment. Another was scheduled for four nights, but was granted a vacation after the study began and was reduced to two nights. Two participants were members of the float pool and received their assignments from the staffing office on a nightly basis, therefore only being able to participate when assigned to one of the three study-approved units. One float pool participant was lost to attrition because of her staffing assignments during the study. Once a participant had completed the control (no nap but testing) and the intervention (nap), any remaining envelopes were withheld and destroyed. 
Self-testing was completed for the control three times during the shift: before shift, mid-shift, and end of shift. Likewise, self-testing for the intervention was completed before shift, mid-shift, and end of shift with additional testing after the nap. The battery of testing averaged six to seven minutes to complete. Participants placed all completed SSS, FAS, and the Palm TXO from each test session in a locked box which was carried by the researcher from unit to unit during the study. The locked box was never left on premises between shifts.

Participants had the option of completing 'before shift' testing before the shift began or within one half hour after starting their shift. The latter allowed time to receive report from off-going staff, therefore disrupting as little as possible the normal work habit of the study participants and non-participating staff. Participants were allowed to test wherever on the unit it was convenient, which meant that some chose to test in a private or secluded area and some among other staff in the nurses' station or lounge.

Control mid-shift testing was completed between 2 a.m. and 3 a.m; intervention midshift self-testing was completed before the nap, which occurred between 2 a.m. and 4 a.m. Providing a time range to complete the intervention afforded participants the ability to coordinate their nap time with their work load, therefore increasing adherence to the intervention.

Participants chose their nap time according to break schedules, patient assignments, or when their sleepiness was routinely greatest. The researcher coordinated the naps, avoiding any two persons napping at the same time on any unit. The after nap self- 
testing was completed within 10 minutes of the nap. The end of shift self-testing was completed within the half hour before or after the end of each participant's shift.

The 20 minute nap fell within each participant's allotted 30 minute break time. An alarm clock was set for 20 minutes by the researcher once a participant went into each unit's designated napping area. The researcher was present on the unit during each participant's nap to answer call lights or get further assistance as needed. This was done to ensure that the participant was undisturbed and awaken after 20 minutes.

A snack was offered to both the nap group and the no-nap group during their 30 minute break, with the intervention group taking their snack after the nap. Protein snackss (low fat cheese or peanut butter) served with whole grain crackers or fruit were chosen since they provide sustained energy longer than high-fat, fried or sugary foods ('Nightshift blues", 2007; "Nutrition Tips for Shift Workers", 2008).

\section{Basic Analysis Plan}

Demographic data was summarized using basic descriptive statistics. Quantitative data derived from the baseline, during, post-nap, and end of shift scores on the dependent variable measures was examined within and between individuals. Descriptive data from the sleep journals was summarized, identifying any themes. For the purpose of this study, data related to the journals was not analyzed at this time. 


\section{Results}

Demographics. All participants were female, and ages ranged from 34 years to 66 years old $(M=45.2 ; S D=10.3)$. The median age was 43 years old. Six participants were registered nurses, one was a licensed practical nurse, and three were certified nurse's aides.

Table 1.

Career and shift work experience $(N=10)$

\begin{tabular}{|lcccc|}
\hline & Years in role & $\begin{array}{c}\text { Years at } \\
\text { test facility }\end{array}$ & $\begin{array}{c}\text { Years of shift } \\
\text { work }\end{array}$ & $\begin{array}{c}\text { Years of shift work at } \\
\text { test facility }\end{array}$ \\
\hline Mean & 17.6 & 13.6 & 11.5 & 10.6 \\
\hline SD & 9.6 & 12 & 12.3 & 12.8 \\
\hline Median & 19 & 7 & 7.2 & 2.8 \\
\hline Least & 4 & 2 & 2 & 31.5 \\
\hline Greatest & 31.5 & 31.5 & 31.5 & 2 \\
\hline
\end{tabular}

Four were full-time employees ( 36 to 40 hours per week) and six were part-time employees (16 to 32 hours per week). Most worked the traditional 11p.m.to 7:30 a.m. shift $(\mathrm{n}=7)$ with the remaining participants working a non-traditional twelve hour shift (7p.m. to 7:30 a.m.; $n=3$ ). Years of experience in their roles ranged from 4 years to 31.5 years, findings that were similar to length of shift work (Table 1). One participant reported that her entire nursing career (31.5 years) had been at the test facility and that she had been a shift worker during that entire time. None reported having a known sleep 
disorder or taking any medication for a sleep disorder. Only one was a smoker, and most $(n=9)$ reported "yes" or "sometimes" to caffeine use during their shifts.

Napping. Participants were asked to indicate on the final page of the journal whether they were able to fall asleep, and if so, how long they slept, how well they slept, whether they woke during their sleep session, whether they dreamt, and how long they lay in bed before getting up. Only seven out of ten journals were returned to the researcher (one participant lost her journal, one did not use her journal, and one did not return her journal). However, for those participants who lost or did not return journals, the researcher provided a copy of the 'nap at work' page to be completed separately. Three participants who returned completed journals did not complete the 'nap at work' page, so while it is known that they rested for 20 minutes, it is not known whether they napped or not. Only one participant reported that she did not fall asleep.

Six participants reported that they were able to fall asleep, taking from a few minutes $(n=1)$, five minutes $(n=2)$, ten minutes $(n=2)$, to fall asleep. One participant reported that she fell asleep immediately and slept the full 20 minutes. Only one reported dreaming. Those participants who responded to the question, 'how well did you sleep', stated that they slept fair $(n=1)$, good $(n=3)$, or very well $(n=1)$ with one person noting that there was not enough time to sleep well.

Stanford Sleepiness Scale. As shown in Table 2, for both the control and intervention situations, most reported a rating of $2(\mathrm{M}=2 \pm 1.3)$ ('functioning at high levels, but not at peak; able to concentrate') when completing the SSS at the beginning of the shift, and by mid-shift, results declined only slightly $(\mathrm{C}:-0.4, \mathrm{I}:-0.7)$. By the end of the control 
shift, most participants reported their sleepiness as a 3 ('awake, but relaxed; responsive but not fully alert') $(M=3 \pm 1.4)$. One participant reported levels of sleepiness during the control of 5, 5, and 6 respectively, more than 4 points beyond the standard deviation.

Table 2.

Stanford Sleepiness Scale (SSS) Results ( $N=10)$

\begin{tabular}{|c|c|c|c|c|c|c|c|c|c|c|c|c|}
\hline \multicolumn{6}{|c|}{ CONTROL (NO NAP W/ TESTING) } & \multicolumn{7}{|c|}{ INTERVENTION (NAP W/ TESTING) } \\
\hline & & & & End & & & & & & & End & \\
\hline & & Mid & & of & & Before & Before & & After & & of & \\
\hline Subjects & Shift & Shift & $\Delta$ & Shift & $\Delta$ & Shift & Nap & $\Delta$ & Nap & $\Delta$ & Shift & $\Delta$ \\
\hline 1 & 3 & 5 & -2 & 3 & 2 & 1 & 3 & -2 & 5 & -2 & 2 & 3 \\
\hline 2 & 1 & 2 & -1 & 5 & -3 & 1 & 1 & 0 & 2 & -1 & 2 & $\overline{0}$ \\
\hline 3 & 2 & $\overline{1}$ & 1 & 2 & -1 & 3 & 3 & 0 & 1 & 2 & 1 & 0 \\
\hline 4 & 2 & 3 & -1 & 3 & 0 & 3 & 2 & -1 & 3 & -1 & 4 & -1 \\
\hline 5 & $\overline{3}$ & 3 & 0 & 3 & 0 & 1 & 2 & -1 & 3 & -1 & 2 & 1 \\
\hline 6 & 5 & 5 & 0 & 6 & -1 & 6 & 5 & 1 & 2 & 3 & 1 & 1 \\
\hline 7 & 1 & 2 & -1 & 2 & 0 & 2 & 2 & 0 & 2 & 0 & 2 & 0 \\
\hline 8 & 1 & 1 & 0 & 2 & -1 & 1 & 3 & 2 & 1 & 2 & 1 & 0 \\
\hline 9 & 1 & 1 & 0 & 2 & .2 & 1 & 2 & -1 & 2 & 0 & 1 & 1 \\
\hline 10 & 1 & 1 & 0 & 2 & -1 & 1 & 2 & -1 & 1 & 1 & 1 & 0 \\
\hline MEAN & 2 & 2.4 & -0.4 & 3 & -0.7 & 2 & 2.5 & -0.7 & 2.2 & 3 & 1.7 & 2.7 \\
\hline SD & 1.3 & 1.6 & & 1.4 & & 1.6 & 1.1 & & 1.2 & & 0.9 & \\
\hline
\end{tabular}

Range of Scores: 1 = 'feeling active, vital, alert, or wide awake' and $7=$ 'no longer fighting sleep, sleep onset soon; having dream-like thoughts'

$\Delta=$ change in scores between each set of testing

Reports of sleepiness after the nap $(M=2.2 \pm 1.2)$ showed little change from before the nap 
$(2.5 \pm 1.1)$. However, while a reduction in sleepiness was not seen immediately following the nap, the end of shift SSS results demonstrated a reduction in sleepiness $(M=1.7 \pm 0.9)$. A Mann-Whitney Rank Sum Test was performed to determine significance on two groupings of test results: (1) intervention after the nap and intervention end of shift, and (2) control end of shift and intervention end of shift. The first test group (after the nap and end of shift in the intervention) did not show any significant difference $(p=0.069)$, in fact some participants $(n=4)$ reported an increase in sleepiness after the nap as compared to before the nap. One person, who already showed a significant increase in reported sleepiness from (1) "feeling active, vital, alert, or wide awake" at the beginning of the shift to (3) "awake, but relaxed; responsive but not fully alert" prior to the nap, reported (5) "foggy; losing interest in remaining awake; slowed down" almost immediately after the nap. Another person reported a reduction in sleepiness from the beginning of the shift (1) "feeling active, vital, alert, or wide awake" to before the nap (2) "functioning at high levels, but not at peak; able to concentrate" to (3) "awake, but relaxed; responsive but not fully alert" after the nap. However, by the end of the shift, (three to five hours after the nap), two of the four who reported an increase in sleepiness after the nap, reported a decrease in their level of sleepiness with ratings equal to or better than their start of shift rating, Only one participant reported an increase in sleepiness by end of shift compared to the start of shift in both the control (3) "awake, but relaxed; responsive but not fully alert", and intervention (4) "somewhat foggy, let down".

The Mann-Whitney Rank Sum Test on the second group (end of shift without a nap compared to end of shift with a nap) showed that the difference in median values between 
the two groups was greater than would be expected by chance and demonstrated a statistically significant difference $(\mathrm{p}=0.017)$. Sleepiness had been reduced almost $50 \%$ (43\%) after the nap $(M=1.7)$ compared to the shift without a nap $(M=3)$. When the mean SSS scores are compared between the eight hour and 12 hour shift workers within the control, the difference is slight ( eight hour $M=2.4 ; 12$ hour $M=2$ ). The same is seen when the test results are compared within the intervention (eight hour: $\mathrm{M}=2.2$; twelve hour: $M=1.8$ ). In this study, sleepiness was not affected by shifts $\leq 12$ hours.

Fatigue Assessment Scale. The FAS score was determined by summing all items. Items 4 and 10 on the FAS required reversed scoring. FAS scores are divided into three groups: scores of 10 to 21 (not tired); 22 to 34 (tired); and 35 to 50 (extremely tired) (Michielsen, Drent, Peros-Golubicic, \& De Vries, 2006). Mean scores for each test condition of the control indicated that most staff were tired when they arrived at work $(M=23, \pm 7.5)$ and remained that way throughout the shift, reporting highest levels of fatigue around 2 a.m. (M = 24.1, \pm 6.3$)$, with little improvement by end of shift $(M=$ $22.3, \pm 9.1$ ) (Table 3). One participant failed to score nine out of 10 of the statements on the FAS during the control end of shift testing. When that fatigue score is discarded, the adjusted mean fatigue score $(M=24.7, \pm 7.0)$ showed that fatigue was greatest at the end of shift.

There was a similar pattern of fatigue among staff during the intervention in which most reported to work tired (FAS $\geq 22 ; \mathrm{M}=23.9, \pm 7.5$ ) and remained tired with little improvement until the nap between 2 a.m. and 4 a.m. $(M=23.2, \pm 6.3)$. After the nap, the mean scores dropped below 22 (not tired) $(M=21.5, \pm 6.6)$ and the decrease in fatigue 
was sustained through the end of shift $(M=21.7, \pm 6.9)$. One participant's mean score $(M=38, \pm 1.6)$ across all testing conditions placed her in the extremely tired ( 35 to 50$)$ group.

Table 3.

Fatigue Assessment Scale (FAS) scores $(N=10)$

\begin{tabular}{|c|c|c|c|c|c|}
\hline & Mean & SD & Median & Lowest & Highest \\
\hline \multicolumn{6}{|l|}{ No nap with testing } \\
\hline Before shift & 23.5 & 7.5 & 24 & 11 & 38 \\
\hline Mid-shift & 24.1 & 6.3 & 24 & 14 & 36 \\
\hline End of shift & 22.3 & 9.1 & 22.5 & $* 1$ & 39 \\
\hline \multicolumn{6}{|l|}{ Nap with testing } \\
\hline Before shift & 23.9 & 6.6 & 23 & 16 & 38 \\
\hline Before nap & 23.2 & 8.7 & 21.5 & 11 & 41 \\
\hline After nap & 21.5 & 6.9 & 20.5 & 10 & 37 \\
\hline End of shift & 21.7 & 6.9 & 21 & 10 & 37 \\
\hline \multicolumn{6}{|c|}{$\begin{array}{l}* \text { Only one out of ten items answered by one participant; adjusted results } \\
\text { test discarded: } M=24.7, S D=7.0, \text { median }=23 \text {, lowest }=15 \text {, highest }=39\end{array}$} \\
\hline
\end{tabular}

A Mann-Whitney Rank Sum Test performed on the FAS scores for the control group at end of shift and the intervention group at end of shift was not significant.

Likewise, significance testing performed between FAS scores after the nap and at the end of the shift in the intervention failed to show significance. 
A comparison of eight and 12 hour shift workers' FAS scores in the control showed that the length of shift had no affect on fatigue scores (eight hour $\mathrm{M}=23.4 ; 12$ hour $\mathrm{M}=$ 22.0 ), with both groups considered to be tired ( $>21)$. Likewise, among the intervention FAS scores, no significant differences were seen between the shift lengths (eight $\mathrm{M}=$ $22.9 ; 12 \mathrm{M}=21.75)$,

Comparison of SSS and FAS scores by groups. When mean results of each test condition in the control and intervention groups for the SSS and FAS were compared, almost identical trends were identified. Participants reported on the SSS that they arrived to work able to concentrate, but not at peak and corresponding FAS scores indicated slight fatigue. Similarly, self-reports of fatigue and sleepiness increased somewhat by mid-shift in the control (SSS: $\Delta=-0.4$ FAS: $\Delta=1.1$ ) and the intervention (SSS: $\Delta=-0.7$; FAS: $\Delta=-0.7$ ). Likewise, the end of shift reports of sleepiness, that of not being fully alert in the control group, mimicked the fatigue score of being tired in the same test condition. When the after nap SSS scores are compared to the after nap FAS results, the decline in sleepiness $(\Delta=3)$ mimicked the decline in fatigue $(\Delta=1.7)$, and is maintained through the shift as demonstrated by SSS results $(\Delta=2.7)$ and FAS score $(\Delta=-1.7)$ at the end of the intervention shift. While the trends appeared to correlate sleepiness with fatigue, the Pearson correlation coefficient testing failed to show significant correlation in all test conditions except for the intervention end of shift, which showed that as sleepiness declined, so did fatigue ( $\alpha=0.05 ;|r| \approx 0.712>0.632)$.

Psychomotor Vigilance Task. The raw data recorded for each PDA-PVT test session consisted of response time, response type (e.g., valid, anticipatory, wrong button), and 
elapsed time from the start of session. By placing the Palm TXO in its cradle, the collected data can be transferred to the Windows companion program, where it can be viewed and saved for statistical analysis. However, because of software incompatibility with the Palm TXO and the researcher's personal computer, synchronization of the data from the Palm TXO to the Windows program was not able to be performed. As soon as this problem was recognized after the first night, individual pocket-sized cards (Appendix G) were developed by the researcher to record reaction times provided on the Palm TX( screen at the end of each test session. Cards were returned to the lock box at the end of each shift. Therefore, PVT data recording lapses and invalid responses is unavailable for this study.

The performance vigilance task tracked the direction of changes in functioning as sleep deprivation increased. As seen in Table 4, mean score changes between the beginning of shift and the mid-shift response time results in the control was less than one hundredth of a second $(0.077)$, and by the end of shift, mean score change was slightly more than half a hundredth of a second (0.056). Mean score changes between the beginning of shift and mid-shift intervention group response time worsened by almost half a hundredth of a second (-0.044), improving after the nap by almost one tenth of a second (0.977). However, by end of shift following the nap, the mean response time change showed a decline in reaction time by almost a half a hundredth of a second (-0.044). MannWhitney Rank Sum Test failed to yield significance between test conditions.

When reaction times are compared between the eight and 12 hour shift workers during the control, the 12 hour workers are almost but not quite a second slower $(-0.095)$ than 
the eight hour workers. However, when the nap was introduced into the shift, the 12 hour workers increased their reaction time scores by almost a quarter of a second $(0.022)$.

Table 4.

Psychomotor Vigilance Task scores $(N=10)$

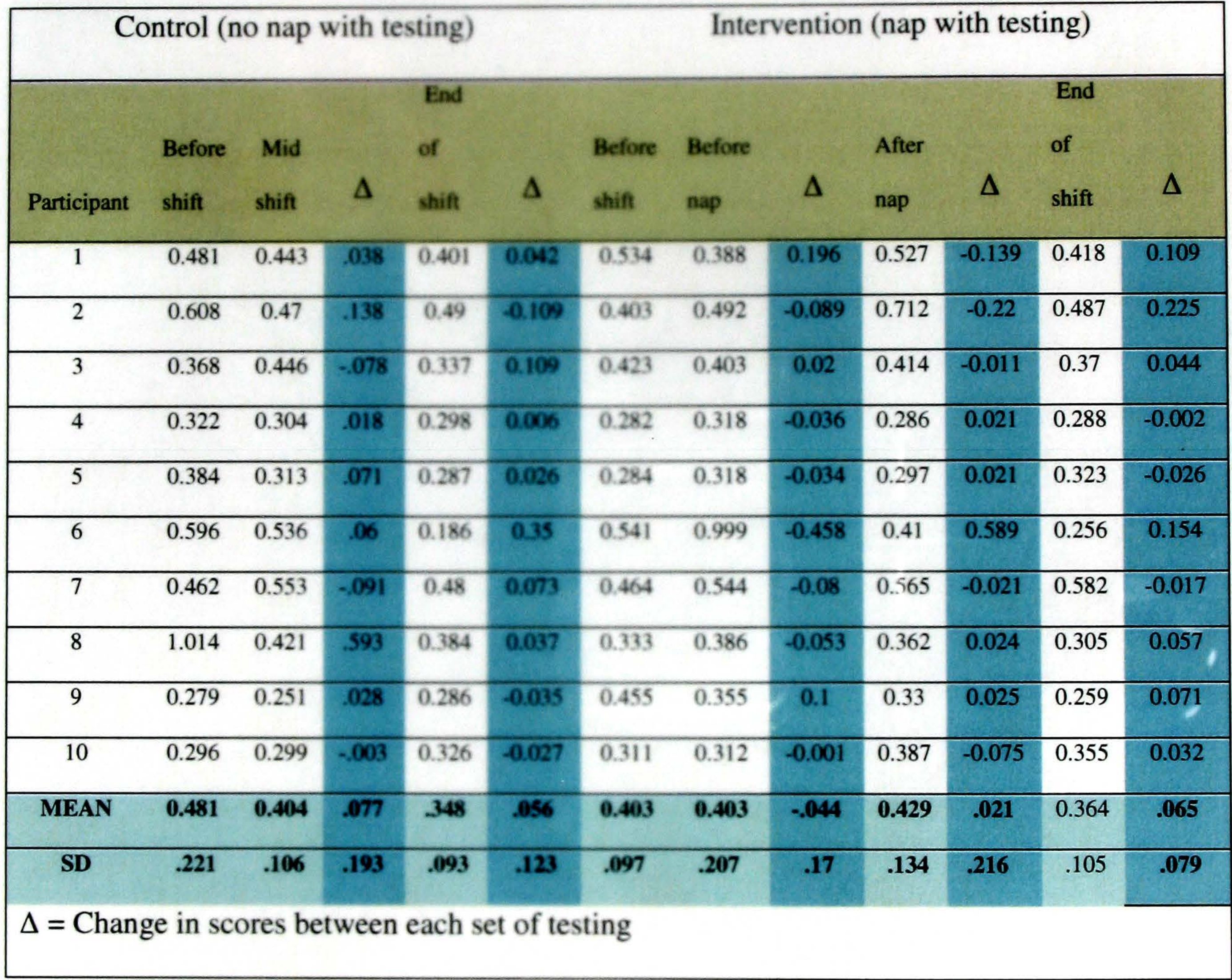

When the control and intervention scores are compared within each shift design, the eight hour workers showed an increase in reaction time (-0.037 seconds), whereas the 12 hour shift workers showed an increase in reaction time of almost a second (0.80). Thus, the 12 
hour shift workers' reaction time appeared to exhibit a greater benefit from a nap during their shift as compared to the eight hour shift workers' reaction time.

In summary, more than half of the participants $(n=6)$ were able to fall asleep during all or part of the 20 minute nap period. Sleepiness was reported to be higher at the end of the shift when no nap was taken than when participants napped. Fatigue and sleepiness peaked by mid-shift in both the control and intervention, and following the nap, decreased and was sustained through the shift. 


\section{Summary and Conclusions}

This quasi-experimental study was performed to determine whether a 20 minute nap during the night shift could reduce sleepiness and fatigue and improve cognitive functioning among nursing shift workers. Ten nurses and nurse's aides were exposed to the control (testing with no nap) and the intervention (nap with testing). Each one completed a battery of tests (self-administered tests of sleepiness and fatigue, and a computerized reaction time test on a PDA) four times during their shift when randomly assigned to the intervention, and three times when randomly assigned to the control. Summary of Results

Sleepiness. While there was statistical significance between sleepiness at the end of the intervention shift as compared to the control end of shift, and no statistical significance was shown between after the nap and the intervention end of shift, trends suggested a reduction in sleepiness. These findings support the growing body of evidence that napping during shift work is an effective intervention against fatigue.

Of concern in this study is the fact that some participants reported increased sleepiness after the nap which could be more indicative of sleep inertia than sleepiness. Sleep inertia, which is a state of moving toward wakefulness, diminishes within one hour after awakening (Miccoli, Versace, Koterle, \& Cavallero, 2008). Participants were asked to complete testing almost immediately upon waking. This finding has real-life implications when nursing staff are expected to react to emergency situations immediately upon awakening. Bruck \& Pisani (1999) found that sleep inertia reduces decision-making performance for at least 30 minutes following a nap when the 
complexities of tasks are increased. Takahashi, Arito \& Fukuda (1999) found that the longer the nap ( $>1.5$ hours), the worse the effects of sleep inertia. Minimizing the nap to 20 minutes within a 30 to 45 minute break would allow time for sleep inertia to recede before staff members resume his/her workload.

Fatigue. The fact that staff arrived to work tired (FAS $>22,<35)$ as demonstrated by the FAS scores ( $\mathrm{C}: \mathrm{M}=23.5 ; \mathrm{I}: \mathrm{M}=23.9)$ supports the literature that shift work is a cause of fatigue often due to shortened sleep sessions of less than the recommended seven to eight hours before work. Regular rest breaks at work free of patient responsibilities are intended to reduce subjective fatigue and improve performance. Tucker (2003) stated that workers not only should be given time to take adequate rest breaks, but should be encouraged to do so.

During this study, nursing staff were forced to take a 30 minute break as a requirement of the intervention. On control nights, work demands, staffing, and preconceived beliefs about rest breaks (i.e. going to the bathroom, having a drink, or sitting while charting constitutes a rest break) may have prevented staff from taking a rest break and completely stop working, thus resulting in the higher FAS scores throughout the night. Rogers, Hwang \& Scott (2004) found that nurses reported taking a break free of patient responsibilities less than half of the shifts they worked. This researcher observed only one unit scheduling break times without patient responsibilities, considering staff preference for time of break. It was observed that breaks on the other two units occurred irregularly, usually when they were 'all caught up', not when fatigued, 
and that nursing staff were not relieved of patient responsibilities, leading to interrupted and shortened break times.

Cognitive Function. The five minute PDA-PVT was a reasonable amount of time for completion as part of the bundle of self-testing, especially with repeated testing throughout the shift. Unfortunately, because of the limited amount of time between recruiting participants and beginning the study, there was no time for participants to attend a pre-study training session on using the PDA-PVT. Lamond, Dawson, and Roach (2005) recommended three practice sessions before starting the study to minimize effects associated with learning. Prolonged reaction times ( $>500$ milliseconds) recorded by several participants at the beginning of their shifts in both the control and the nap could be interpreted as a function of learning rather a function of fatigue because of such long reaction times. It is essential that further studies employing the PDA-PVT include such a practice session.

Napping. Participants were encouraged to nap, but not expected to nap. While the goal of this study was to explore the effects of napping on sleepiness in nursing staff, for some of the participants, a 20 minute rest period away from the unit, sanctioned by the administration without chance of any disciplinary action, appeared to be as effective in reducing sleepiness as falling asleep. Hayashi et al. (2004) showed that a 20 minute rest during shift work restored sleepiness, even if only for an hour or so. For some, it was their first night working after consecutive days off. It is possible that those participants could have had a different sleeping pattern (a restorative full night sleep) instead of 
shortened daytime sleep sessions commonly found with shift workers and were not bothered by fatigue on the night they napped.

\section{Limitations}

There were several limitations to this study including small sample size, difficulty with recruitment, lack of training sessions, only one nap during the study period, and technical issues with the PDA-PVT. The small sample size was tied to the difficulty with recruitment. The names and addresses provided to the researcher by the hospital's Nursing Department incorrectly included persons who were ineligible by their shift assignments and did not include those that were eligible. Therefore, eligible participants did not receive the invitational letter. Because of the time constraint, the face to face informational session campaign was limited to two nights and only captured those workers scheduled on those nights. It was also difficult to explain the study during the sessions because staff was not able to completely stop working, but answered phone calls and patient call lights, charted, or passed medications. A formal educational session may have yielded more participants. But of note is the fact that despite a small sample size, significance was shown between sleepiness at the end of the shift in the control and the intervention. A training session which included time to complete the battery of tests could have minimized learning effects which may be reflected in some of the test results. Again, a formal educational session would have provided the venue for training.

Another limitation of this study was the fact that staff napped only once during the study, and due to randomization, not necessarily on a night when they were most tired. 
Also, napping during work is not an established practice for these participants and some may have needed several nights to establish a habit of napping.

The inability to analyze PVT data other than mean reaction times because of technical issues was a limit of this study. Loh et al (2004) stated that as sleepiness increased, problem solving and reasoning abilities became slower, and false responding increased. Whereas mean RTs provided a general measure of performance capability, deterioration in performance is demonstrated within the optimal response domain (fastest $10 \%$ of RT), which cannot be extrapolated from the data.

\section{Conclusions}

This study demonstrated that nursing shift workers who experience fatigue and sleepiness could benefit from a nap during their shift. The benefit of a nap was shown to be sustained through the shift. Replication of this research should include a greater number of participants from all nursing divisions within the acute care setting, i.e., medical-surgical, intensive care, emergency, surgical services, psychiatric, and rehabilitation. Any replication studies should not be limited to introducing a single nap, but include multiple naps for each participant, and on nights when the participants are fatigued. 
Recommendations and Implications for Advanced Nursing Practice

This study has shown that managing sleepiness and fatigue with a nap during shift work is beneficial for staff and ultimately their patients. Sleep deprived health care workers pose harm to themselves and to their patients. Shift workers sleep six or fewer hours per day, considerably less than the recommended seven to nine hours of sleep per night needed for optimal performance (NSDRP, 2003; NSF, 2008; Rogers, 2008). Medical errors that the IOM (1999) report stated were preventable and which health care staff fatigue are likely a contributing factor include: administering the wrong medication or medication dose; failure to recognize relevant clinical findings; misinterpretation of clinical data; mishandling of sharps; neglecting to initiate warranted interventions; and using less than strict infection control practices (Alspach, 2008). The National Sleep Disorders Research Plan (2003) recommended finding ways to prevent fatigue-related medical errors by nursing staff that could save thousands of patient lives each year.

There is a growing body of evidence that acknowledges that the need for $24 / 7$ operation in health care has increased fatigue related errors and accidents. This recognition has led to the development of fatigue management programs that are preventive (e.g., education about the biological basis of fatigue) and operational (e.g., naps in the workplace). If optimal napping strategies can be found to manage sleepiness and its cognitive, psychomotor, and clinical effects, this can form a basis for evaluating evidenced-based model fatigue management to determine the extent to which fatiguerelated risks can be reduced. 


\section{Recommendations}

Organizational recommendations. The National Sleep Foundation 2008 Sleep in America Poll showed that those respondents whose employers did not allow or did not know if their employer allowed naps during breaks would take breaks at work if allowed. The IOM report Keeping Patients Safe: Transforming the Work Environment of Nurses (2004) recommended the development and testing of methods to help night shift workers compensate for fatigue as an evidence-based policy to increase patient safety. The introduction of fatigue management programs that include napping in healthcare organizations call for program evaluations that are linked to patient, as well as staff, outcomes.

The IOM (2006) stated that adequate public health education around sleep loss and sleep disorders includes not only informing the public and health providers but developing adequate surveillance and monitoring of the public health burden. Linking fatigue management programs to patient outcomes must be an interdisciplinary approach, including nursing, medicine, administration, pharmacology, and risk management. Included in fatigue management programs should be a procedure for identifying shift work sleep disorder by routine screening of shift workers, and enabling employees tó transfer to a day shift, if possible, if shift work has become detrimental to their health.

While napping in health care settings has yet to be widely accepted or instituted by health organization or the nursing profession, successful programs have been instituted. The Veterans Administration (VA) Palo Alto instituted a strategic nap program whose key elements for implementation included an educational program and staff 
empowerment (Agency for Healthcare Research and Quality, 2010). The strategic nap program was not meant to test efficacy of napping as this had already been proven through research, but focused on the implementation of a napping program within the complex work environment of the hospital setting. After a successful implementation at the VA Palo Alto campus, a second VA hospital chose to include a napping program. The VA National Center for Patient Safety (NCPS), in conjunction with its researcher, has submitted a proposal to the American Institute of Architects' Health Revisions Guideline Committee to include a requirement for staff nap areas in the 2010 edition of the Guidelines for the Construction of Hospitals and Healthcare Facilities (Howard, 2008).

Legal recommendations. Some employers consider napping while on düty a misdemeanor and a breach of contract (Peate, 2007). Alspach (2008) stated that sleeping on the job has been viewed as "irresponsible, immature, indolent, and/or indisputable evidence of disinterest in maintaining employment " (p. 12). Although most employers do not allow napping in the workplace, a ban on napping may soon prove to be a legal liability as the body of evidence in favor of napping grows. Thus, efforts to make workplace policies nap-friendly may soon gain popularity as the issue increases in global significance (NSF, 2008).

Recommendations for future research. What were noticeably missing from this study were staff reports of patient incidents and near misses that were attributed to sleepiness and fatigue. Suggested research questions related to nursing fatigue and patient outcomes 
include: how often do errors occur; do staff report near-misses; and how safe do nurses believe themselves to be when working nights?

Since patient safety is related to nursing fatigue, further studies should include patients' perception of shift workers and their safety. Suggested questions include: how cognizant were patients of their nurse's state of fatigue; how safe patients felt during the night; and whether those patients who experienced an untoward event during the night attributed the incident to staff fatigue.

As Ajzen (2006) stated, planned behavior comes from a change in one or more of the behavioral beliefs. If napping is to become an accepted behavior in shift work, then understanding the attitude toward the behavior (in favor or not in favor of napping) must occur before change is seen. Further research needs to focus on nurses' perception of napping. Some suggested research questions around perception include: how nurses perceive napping, including administration and the profession; what is the disposition of nurses toward napping; and whether nurses' attitudes toward napping are related to demographics, i.e. age, shift worked, years of experience.

Another recommended study around sleep inertia would be to test sleepiness immediately following the nap and at varying intervals during the remaining break. Those findings would be used to determine optimal break lengths that include not only a nap but time for the effects of sleep inertia to dissipate before staff are required to resume their duties.

Recommendations for research funding. The 1993 NIH Revitalization Act authorized the creation of the National Center for Sleep Disorder Research for the conduct and 
support of research, training, health information dissemination, and other activities related to sleep disorders, and to coordinate with similar activities of other federal agencies (IOM, 2006). These federal agencies included the Center for Disease Control and Prevention, Department of Defense, Department of Transportation, Occupational Safety and Health Administration. and Department of Veterans Affairs. The National Institute of Health funding for sleep loss and sleep disorder research has increased by more than $150 \%$ since the NCSDR became fully operational in 1996 (IOM, 2006). However, as the NIH budget has plateaued, so has grant funding for sleep-related projects with a $27.4 \%$ decrease in 2004 from the previous year (IOM). Additional funding for nursing research needs to be available, especially as the public and policymakers become more aware of the role of nursing related to patient safety research.

Recommendations for mursing education. Rogers (2008) recommended that nurses get seven to eight hours sleep in a 24 hour period, and that younger nurses (those 20 to 30 years) should be particularly careful about obtaining adequate sleep as their performance is more adversely affected by insufficient sleep. In order to institute these recommendations, many nurses would have to make substantial behavioral changes. Educating veteran nurses about the effects of insufficient sleep on their health and patient safety is vital if any behavior change is to be realized. Even more important is educating undergraduate nursing students to the effects of insufficient sleep since graduate nurses are more likely to enter the workforce as shift workers. 
Implications for Advanced Practice Nursing

Advanced practice nurses function as consultants in their area of expertise, interpret, evaluate, and participate in research, provide clinical and professional leadership, collaborate, and utilize ethical decision making (O'Grady, 2008). The advanced practice nurse (APN) possesses the skill and leadership necessary to lead patient safety initiatives in health care systems. The APN's education prepares her/him for researching the effects of fatigue on patient safety and disseminating that information to nurses, nursing leaders, health care administrators, and policy makers.

Implications for nursing research. The body of nursing research including napping and other fatigue management interventions must continue to grow. The IOM (2004) called for heath care organizations to use research findings to add to their range of patient safety practices. Nursing research is important to the APN because it addresses questions that require observational and quasi-experimental design studies to determines the effectiveness of interventions, such as napping.

Rogers (2008) reported that employees from a variety of industries have been exposed to fatigue countermeasure programs, but there is limited information about their efficacy. What was noticeably missing from this study was data on whether patient safety was compromised when nursing staff experience fatigue.

Findings from APN research must be published, not only in scholarly nursing journals, but in journals outside of nursing in order to reach a broader public and policymaking audience. Key policymakers as well as the public would be made more aware of the 
contributions of APNs to improving the quality of patient care and safety and reducing costs when APNs' accomplishments are published.

Without the engagement of the nursing workforce, who are closest to bedside care and patient safety, solutions to staff fatigue are unlikely to be achieved or sustained. The nursing workforce must be engaged in the process of implementing fatigue management programs in order for such programs to become a part of nursing practice. Anthony and Anthony (2005) emphasized the importance of bridging knowledge gained from scientific research into places where people work which can impact the working force's quality of life. Disseminating research results to the workforce through organizations and media is a fundamental role of the APN.

Implications for partnering with key stakeholders. Advanced practice nurses are most proficient at identifying key stakeholders who can affect policies surrounding patient safety. Key stakeholders include nurses, nursing and healthcare administrators, nursing unions, nurse educators, the sleep community, occupational health physicians and nurses, quality asssurance, and health insurers. As the role that napping plays in reducing patient incidents and near misses is recognized among the stakeholders, policies can gain support at the micro (organization napping policy) and the macro levels, for example the inclusion of napping sites in Guidelines for the Construction of Hospitals and Healthcare Facilities (Howard, 2008). It is easier for the individual nurse to influence policy at the micro level. Influencing policy at the macro level requires large numbers and organized nurses, often led by the APN. 
Leadership. The APN can advance to senior leadership roles within healthcare and professional organizations, thereby exerting influence on policy making at the national, state, and local levels. The American Association of Colleges of Nursing added health policy to the domains of knowledge needed by nurses with advanced educations (Taft \& Nanna, 2008). If the APN is to play a role in delivering evidence-based messages that communicate the essence of a body of research, then she/he must be viewed as a credible source by decision makers. The APN is deemed credible by her/his advanced communication skills/processes to lead patient safety initiatives in health care systems.

Advanced practice nurses in senior leadership roles are required to understand the policies that affect their organization, the process through which such policies are made, and all the forces that can affect the process and its outcomes (Hewison, 2008). Changes in policy can be slow and incremental or such changes can be rapid as when a crisis hits. Kingdon (2006) stated that policy occurs when three streams (problems, proposals, and politics) come together: when a problem is recognized; when policy alternatives are available for that problem; and when the political condition is right. But the policy window is opened for only a brief time before it closes and does not open again for some time. The APN recognizes that policies must be developed before the actual opportunity for consideration or adoption presents itself, because when the window opens there is no time to create a proposal.

The APN in a leadership role recognizes the problem of patient safety related to nursing fatigue through research and scholarly journals. Once recognized, the APN is able to develop solutions to the problem, such as napping policy or regulation. 
Professional sources provide the APN with great opportunity to voice policy preferences. Advanced Practice Nurses in leadership roles belong to special interest groups that help to advance the solution, including professional organizations such as the American Nurses Association, American Association of Occupational Health Nurses, and American Public Health Association Public Health Nurses section. It is important for APNs to be included in multidisciplinary organizations, such as the Joint Commission, while limited, provides an opportunity for nurses to voice professional preferences.

When the policy window opens, such as when there is a change in administration, the scheduled renewal of enabling legislation or the publication of a national report, the APN realizes this special opportunity to advance policy change. It was the release of the 1999 IOM report, To Err is Human: Building a Safer Health System, that publicized the widespread problems related to patient safety in the United States and called for dramatic changes in health care delivery.

In summary, the APN is critical to advancing napping for shift workers because she/he can interpret, evaluate, and participate in research, create evidence-based policy, and collaborate with key stakeholders. The advanced communication skills that the APN possesses are essential in breaking down barriers against napping in the workplace. The APN possesses the skill and leadership necessary to lead patient safety initiatives and to empower nurses to become proactive in developing policies that are beneficial to the nursing profession and the patients for whom they care. 


\section{References}

Ajzen, I. (2006). Behavioral interventions based on the theory of planned behavior. Retrieved February 16, 2009 from http://www.people.umass.edu/aizen/tpb.html

Åkerstedt, T. (2006). Searching for the countermeasure of night-shift sleepiness [Electronic version]. Sleep, 29, 19-20.

Alspach, G. (2008, December). Napping on the night shift: Slacker or savior [Electronic version]. Critical Care Nurse, 28,12-19.

Anthony, W.A. \& Anthony, C.W. (2005). The Napping Company: Bringing science to the workplace [Electronic version]. Industrial Health, 43, 209-212.

Basner, R. (2005, August). Shift-work sleep disorder - The glass is more than half empty [Electronic version]. New England Journal of Medicine, 353, 519-521.

Berger, A. \& Hobbs, B. (2006, August). Impact of shift work on the health and safety of nurses and patients [Electronic version]. Clinical Journal of Oncology Nursing, $10,465-471$.

Blachowicz, E. \& Letizia, M. (2006, October). The challenges of shift work [Electronic version]. MEDSURG Nursing, 15, 274-280.

Bonnefond, A., Muzet, A., Winter-Dill, A., Bailloeuil, C., Bitouze, F. \& Bonneau, A. (2001).Innovative working schedule: Introducing one short nap during the nightshift [Electronic version]. Ergonomics, 44, 937-945.

Bruck, D. \& Pisani, D. (1999). The effects of sleep inertia on decision-making performance [Electronic version]. Journal of Sleep Research, 8, 95-103. 
Clinical Rounds: Shift Work Study Supports Power Naps (2008, September). Nursing2008, 38, 25.

Creek, R. (2004). Feasibility of methods for evaluating naps for nurses working night shift. ANF Research Grant ID \#2003091.

De Vries, J., Michielsen, H.J. \& Van Heck, G.L. (2003). Assessment of fatigue among working people: A comparison of six questionnaires [Electronic version]. Occupational Environmental Health, 60 (Suppl I), il0-i15.

Dorriann, J., Rogers, N.L. \& Dinges, D.F. (2005). Psychomotor vigilance performance: Neurocognitive assay sensitive to sleep loss. In Kushida, C.A. (Ed.) Sleep deprivation: Clinical issues, pharmacology, and sleep loss effects (pp.39-70). New York, New York: Dekker.

Drake, C., Roehrs, T., Richardson, G., Walsh, J. \& Roth, T. (2004). Shift work sleep disorder: Prevalence and consequences beyond that of symptomatic day workers [Electronic version]. Sleep, 27, 1453-1462.

EatRight Ontario. (n.d.). Nutrition Tips for Shift Workers. Retrieved May 9, 2009, from http://www.eatrightontario.ca/en/ViewDocument.aspx?id=23

Folkard, S., Lombardi, D. \& Tucker, P. (2005). Shiftwork: Safety, sleepiness and sleep [Electronic version]. Industrial Health, 43, 20-23.

Harvey, A., Stinson, K., Whitaker, K., Moskovitz, D. \& Virk, H. (2008). The subjective meaning of sleep quality: A comparison of individuals with and without insomnia [Electronic version]. Sleep, 31, 383-393. 
Hayashi, M., Chikazawa, Y. \& Hori, T. (2004, November). Short nap versus short rest: Recuperative effects during VDT [Electronic version]. Ergonomics, 47, 15491560.

Herscovitch, J. \& Broughton, R. (1981). Sensitivity of the Stanford Sleepiness Scale to the effects of cumulative partial sleep deprivation and recovery oversleeping [Abstract]. Sleep, 4, 83-91.

Hewison, A. (2008, November). Evidence -based policy: Implications for nursing and policy involvement [Electronic version]. Policy, Politics, \& Nursing Practice, 9, 288-298.

Hoddes, E., Dement, W. \& Zarcone, V. (1972). The development and use of the Stanford Sleepiness Scale (SSS). Psychophysiology. 9, 150.

Hughes, R. \& Stone, P. (2004, September). The perils of shift work [Electronic version]. American Journal of Nursing, 104, 60-63.

Humm, C. (2008). Night-shift napping [Electronic version]. Nursing Standard, 22, 20-1. Institute of Medicine. (2006). Sleep Disorders and Sleep Deprivation: An Unmet Public Health Problem. Wàshington, DC: National Academies Press.

Institute of Medicine. (2004). Keeping Patients Safe: Transforming the Work Environment of Nurses. Summary. Washington, DC: National Academies Press. Institute of Medicine. (1999). To Err is Human: Building a Safer Health System. Washington, DC: National Academies Press. 
Kingdon, J. (2002). The reality of public policy making. In M. Danis, C. Clancy, \& L.R. Churchill (Eds.). Ethical dimensions of health policy (pp. 97-116). New York, New York: Oxford.

Kubo, T., Takeyama, H., Matsumoto, S., Ebara, T., Muratá, K., Tachi, N. \& Itani, T. (2007). Impact of nap length, nap timing and sleep quality on sustaining early morning performance [Electronic version]. Industrial Health, 45, 552-563.

Kunert, K., King, M. \& Kolkhorst, F. (2007, August). Fatigue and sleep quality in nursès [Electronic version]. Journal of Psychological Nursing, 45, 31-37.

Lamond, N., Dawson, D. \& Roach, G. (2005). Fatigue assessment in the field: Validation of a hand-held electronic psychomotor vigilance task [Electronic version]. Aviation, Space, and Environmental Medicine, 76, 486-489.

Lamond, N., Jay, S., Dorrian, J., Ferguson, S., Roach, G.D. \& Dawson, D. (2008). The sensitivity of a palm-based psychomotor vigilance task to severe sleep loss [Electronic version]. Behavioral Research Methods, 40, 347-352.

Lindsey, D. (2007, August). Police fatigue: An accident waiting to happen [Electronic version]. FBI Law Enforcement Bulletin, 76, 1-8.

Loh, S., Lamond, N., Dorrian, J., Roach, G. \& Dawson, D. (2004). The validity of psychomotor vigilance tasks of less than 10-minute duration [Electronic version]. Behavior Research Methods, Instruments, \& Computers, 36, 339-346.

Miccoli, L., Versace, F., Koterle, S. \& Cavallero, C. (2008). Comparing sleep-loss sleepiness and sleep inertia: Lapses make the difference [Electronic version]. Chronobiology International (25) 5, 725-744. 
Michielsen, H. J., De Vries, J., Van Heck, G. L., Van de Vijver, F. J. R., \& Sijtsma, K. (2004). Examination of the dimensionality of fatigue: The construction of the Fatigue Assessment Scale (FAS). European Journal of Psychological Assessment, $20,39-48$.

Michielson, H.J., De Vries, J.D. \& Van Heck, G.L. (2003). Psychometric qualities of a brief self-rated fatigue measure The fatigue assessment scale [Electronic version]. Journal of Psychosomatic Research, 54, 345-352.

Michielson, H.J., Drent, M., Peros-Golubicic, T. \& De Vries, J. (2006). Fatigue is associated with quality of life in sarcoidosis patients [Electronic version]. Chest, 130, 989-994.

Millman, R. (2005, June). Excessive sleepiness in adolescents and young adults: Caausesés, consequences, and treatment strategies [Electronic version]. Pediatrics, 115, 17741786.

Mitchell, P.H., Defining patient safety and quality care. from Patient safety and quality: An evidence-based handbook for nurses. (Prepared with support from the Robert Wood Johnson Foundation). Agency for Healthcare Research and Quality Publication No. 08-0043. U.S. Department of Health and Human Services. Rockville, MD.

Monk, T. (2007). Practical consequences of fatigue-related performance failures [Electronic version]. Sleep, 30, 1402-1403.

National Guideline Clearinghouse (n.d.) Practice parameters for the clinical evaluation of circadian rhythm sleep disorders. Retrieved September 15, 2008 from 


\section{$\underline{\text { www.guideline.gov }}$}

National Sleep Foundation (2008). Shift work and sleep. Retrieved December 16, 2008 from www.sleepfoundation.org

National Sleep Foundation. 2008 Sleep in America poll. Summary findings [Electronic version]. Washington, D.C.

Nutrition tips: Night shift blues (n.a.). (2007). Nursing 2007, 37, 78.

O'Grady, E. (2008). Advanced practice registered nurses: The impact on patient safety and quality. In R. Hughes (Ed.), Patient safety and quality: An evidence-based handbook for nurses (pp. 601-620). (AHRQ Publication No. 08-0043). Rockville, MD.

Owens, J. (2007, April/June). Sleep loss and fatigue in healthcare professionals [Electronic version]. Journal of Perinatal \& Neonatal Nursing, 21, 92-100.

Peate, I. (2007). Strategies for coping with shift work [Electronic version]. Nursing Standard. 22, 42-45.

Pigeon, W. R., Sateia, M. J. \& Ferguson, R. J. (2003). Distinguishing between excessive daytime sleepiness and fatigue: toward improved detection and treatment. Journal of Psychosomatic Research. 54, 61-69.

Purnell, M., Feyer, A. \& Herbison, G. (2002). The impact of a nap opportunity during the night shift on the performance and alertness of 12-h shift workers [Electronic version]. Journal of Sleep Research, 11, 219-227.

Reschovsky, C. (2004, March). Journey to work: 2000. In Census 2000 Brief [Electronic version]. Washington, DC: U.S. Census Bureau. 
Rogers, A. (2008) The effects of fatigue and sleepiness on nurse performance and patient safety. In R. Hughes (Ed.), Patient safety and quality: An evidence-based handbook for nurses (pp. 601-620). (AHRQ Publication No. 08-0043). Rockville, MD.

Rogers, A., Hwang, W. \& Scott, L. (2004). The effects of work breaks on staff nurse performance [Electronic version]. Journal of Nursing Administration, 34, 512519.

Rouch, I., Wild, P., Ansiau, D. \& Marquie, J. (2005). Shiftwork experience, age and cognitive performance [Electronic version]. Ergonomics, 48, 1282-1293.

Sallinen, M., Härmä, M., Åkerstedt, T., Rosa, R. \& Outitillqvist (1998). Promoting alertness with a short nap during a night shift [Electronic version]. Journal of SleepResearch, 7, 240-247.

Schwartz, J. \& Roth, T. (2006). Shift work sleep disorder: Burden of illness and approaches to management [Electronic version]. Drugs 2006, 66, 2357-2370.

Schweitzer, P., Randazzo, A., Stone, K., Erman, M. \& Walsh, J. (2006). Laboratory and field studies of naps and caffeine as practical countermeasures for sleep-wake problems associated with night work [Electronic version]. Sleep, 29, 39-50.

Seki, Y. \& Yamazaki, Y. (2006). Effects of working conditions on intravenous medication errors in a Japanése hospital [Electronic version]. Journal of Nursing Management, 14, 128-139.

Shen, J., Botly, L., Chung, S., Gibbs, A., Sabanadzovic, S. \& Shapiro, C. (2006). Fatigue and shift work [Electronic version]. Journal of Sleep Research, 15, 1-5. 
Sleep and Safety (2003) In National Sleep Disorders Research Plan (NIH Publication No. 03-5209, pp. 60-62). Washington DC: U.S. Department of Health and Human Services.

Smith-Coggins, R., Howard, S., Mac, D., Wang, C., Rosekind, M., Sowb, Y. et al. (2006). Improving alertness and performance in emergency department physicians and nurses: The use of planned naps [Electronic version]. Annals of Emergency Medicine, 48, 596-604.

Taft, S.H. \& Nanna, K.M. (2008, May). What are the sources of health policy that influence nursing practice? [Electronic version]. Policy, Politics, \& Nursing Practice, 9, 274-287.

Takahashi, M., Arito, H. \& Fukuda, H. (1999). Nurses' workload associated with 16-h night shifts II: Effects of a nap taken during the shifts [Electronic version]. Psychiatry and Clinical Neurosciences, 53, 223-225.

Takkeyama, H., Kubo, T. \& Itani, T. (2005). The nighttime tap strategies for improving night shift work in workplace [Electronic version]. Industrial Health, 43, 24-29. Tietzel, A. \& Lack, L. (2002). The recuperative value of brief and ultra-brief naps on alertness and cognitive performance [Electronic version]. Journal of Sleep Research, 11, 213-218.

Thorne, D., Johnson, D., Redmond, D., Sing, H., Belenky, G. \& Shapiro, J. (2005). The Walter Reed palm-held psychomotor vigilance test [Electronic version]. Behavioral Research Methods, 37, 111-118.

Tucker, P. (2003, April - June). The impact of rest breaks upon accident risk, fatigue and 
performance: a review [Electronic version]. Work \& Stress, 17, 123-137.

U.S. Department of Health and Human Services. (2003, July). 2003 National Sleep

Disorders Research Plan. (NIH Publication No. 03-5209). Bethesda, MD:

Author.

Wertz, A., Ronda, J., Czeisler, C. \& Wright, K. (2006). Effects of sleep inertia on cognition [Electronic version]. Journal of American Medical Association, 295, 163-164.

Yang, C., Lin, F. \& Spielman, A. (2004). A standard procedure enhances the correlation between subjective and objective measures of sleepiness [Electronic version]. Sleep, 27, 329-332. 
Appendix A

Informational Letter 


\section{An Invitation to Participate in a Nursing Research Study at Our Lady of Fatima Hospital}

You are invited to participate in a research study involving a select group of nurses and nurse's aides at Our Lady of Fatima Hospital in March. I am a master's student in nursing at Rhode Island College. I have also been a nurse at Our Lady of Fatima Hospital for the past 27 years. My research targets all nurses and nurse's aides who work either 11 p.m. -7 a.m. or 7 p.m. -7 a.m. on the medical surgical units. The purpose of the study is to determine what affect a 20 minute nap during a 30 minute break between the hours of 2 a.m. and 4 a.m. might have on sleepiness, fatigue and reasoning. Determining these affects involves you completing approximately 10 minutes of self-testing using one rating scale for sleepiness and a second scale for fatigue, as well as a timed reaction test on a hand held personal assisstant device (PDA) to test reasoning. You will be provided nutritious snacks during the break period.

Within a two week period you will be assigned by chance, like flipping a coin or rolling a dice, to take a nap and complete the testing one night and another night to complete the testing without taking a nap. In addition, during the two weeks you will be asked to keep a daily journal about your sleep habits and how tired you are during each shift. Some other information that will be collected include your age, height, weight, your gender, education, how long you have been in nursing, how long you have been employed at St. Joseph's Health Services of RI, how long you have worked the night shift and which rotation you work, and a brief medical history.

Your name or initials will not appear on any self-rating tests or timed response tests. Instead you will be assigned a unidentifiable number so that your personal information and tests will remain confidential. Records will be kept in a locked file, and access will be limited to me as the researcher, the Rhode Island College review board responsible for protecting human participants, and St. Joseph's Hospital Health Services of RI research oversight committee. The original data will be destroyed within 5 years after the study has been completed.

Your participation in this study is voluntary. You may change your mind and not participate any time after you give consent. There is no penalty or loss of benefits for not participating or for discontinuing your participation. You will be 
Shift Work Napping 60

Prior to the start of the study there will be an orientation which will include discussion about the study with time for questions and answers and practice of the self administered sleepiness and fatigue ratings as well as the reaction timed test. If you are interested in participating or have any further questions about my research, please contact me by phone at $722-4903$ or by e-mail at

- Contacting me to agree to participate in the study grants me permission to contact you further about participating.

It has been proven that safety is impaired when nurses and nurse's aides struggle to stay awake during the second half of a shift, especially at night. Excessive sleepiness and fatigue often leads to performance impairment and diminished attentiveness that may affect job productivity and patient safety. Thank you for considering participating in this research.

Sincerely,

Cheryl Bourdony, RN, BSN 
Shift Work Napping 61

Appendix B

Informed Consent Form 


\section{INFORMED CONSENT DOCUMENT}

St. Joseph's Health Services of Rhode Island

Rhode Island College

[Planned Napping as an Intervention to Reduce Fatigue and Improve Cognitive Function for Shift Workers in Nursing]

You are being asked to participate in a research study about planned napping for nurses and nurse's aides working night shifts. You were selected as a possible participant because you are in a position at Our Lady of Fatima Hospital that includes working between the hours of 7 p.m. and 7 a.m. Please read this form and ask any questions that you may have before agreeing to be in the research.

Researchers at Rhode Island College are conducting this study.

\section{Background Information}

The purpose of this research is to study whether a 20 minute nap when tired during your night shift decreases sleepiness or fatigue, and increases reasoning.

\section{Procedures}

If you agree to be a participant in this research, we would ask you to do the following things: During a 2 week period, you will be assigned by chance, like flipping a coin or rolling dice, once to take a nap during your shift. Several times during your shift you will self-test for sleepiness and fatigue by rating your level of sleepiness and fatigue on a form, and perform a performance response test on a personal data assistant (PDA). You will take these tests 3 times during the shift: soon after you begin your shift; following the nap between 2 a.m. and 4 a.m.; and after your shift. There will also be one night during the 2 weeks that you will be randomly assigned not to nap but to complete the self-tests 3 times during the night at the beginning of the shift; between 2 a.m. and 4 a.m.; and at the end of the shift. You are asked to keep a sleep journal provided by the researcher to write notes about your daily sleep: when you go to bed; how long it takes you to fall asleep; how long you sleep; how well you slept.

\section{Risks and Benefits to Being in the Study}

This research has no foreseeable risks.

The benefits of participation is a broader understanding of how reducing sleepiness and fatigue by napping when you are tired during the night shift may improve reasoning abilities and therefore reduce patient errors. 


\section{Confidentiality}

The records of this research will be kept private. In any sort of report we might publish, we will not include any information that will make it possible to identify a participant. Research records will be kept in a locked file kept at Our Lady of Fatima Hospital, and access will be limited to the researcher, the college review board responsible for protecting human participants, and St. Joseph's Health Services of R.I. research oversight committee. The original data will be stored for at least three years after the study has been completed.

\section{Voluntary Nature of the Study}

Your participation is voluntary. If you choose not to participate, it will not affect your current or future relations with the College or with St. Joseph's Health Services of R.I. There is no penalty or loss of benefits for not participating or for discontinuing your participation.

\section{Contacts and Questions}

The researcher conducting this study is Cheryl Bourdony, RN, BSN. You may ask any questions you have now. If you have any questions later, you may contact her at 722-4903 or 456-3113 or by email at

If the researchers cannot be reached, or if you would like to talk to someone other than the researcher(s) about (1) concerns regarding this study, (2) research participant rights, (3) research-related injuries, or (4) other human subjects issues, please contact Kevin Middleton, Rhode Island College Committee on Human Participants in Research at (401) 456-8753 or write: Kevin Middleton, c/o Rhode Island College Committee on Human Participants in Research at Office of Research and Grants Administration, Roberts Hall, 600 Mount Pleasant Avenue, Providence, RI 02908. In addition, Michele Danish, Pharm.D., (phone 456-3382; emailmdanish@saintjosephri.com) is another resource for anyone who has questions about rights as a research subject or who may want to contact someone other than the investigator.

You will be given a copy of this form for your records.

I have read the above information. I have received answers to the questions I have asked. I consent to participate in this research. I am at least 18 years of age.

This consent is null and void after [usually one year after CHPR approval]. 
Signature of Participant:

Date:

I have explained the study to the participant.

Signature of Researcher:

Date: 
Appendix C

Sleep Journal Pages 
This is your assigned research number:

It is a random number and cannot identify you to anyone else, not even me. Remember this number; you will need to put this number on your demographic information sheet, each of the sleepiness and fatigue tests you complete, and the performance vigilance test. It is used only to match information.

You are being asked to make daily entries about your sleep and sleep habits for the entire 2 weeks of the research study (even nights you are not assigned to work) in this journal. This information is especially important on the nights that you nap and test or don't nap and test. At the end of the journal is a page to record information about the nap you take at work during the study. This information will guide me in interpreting the results of tests.

Please return the journal to me at the end of the study by sending it in an inter-office envelope and mark it:

Cheryl Bourdony MOR

Thank you for participating in my research. 
Day 1-Day 14

Did you sleep before your shift today? Yes No

Did you sleep in the morning or evening, or both?

Morning Evening Both

How many hours did you sleep each time you slept?

Morning ___ Evening

How long after going to bed did you fell asleep?

How well did you slept?

Did you wake up during your sleep session?

Did you dream?

How long did you lie in bed before getting up?

Did you use any sleep aides? 
Nap at Work Information

Did you fall asleep?

Yes

No

How long after going to bed did you fell asleep?

How well did you slept?

Did you wake up during your sleep session?

Did you dream?

How long did you lie in bed before getting up? 
Shift Work Napping 69

Appendix D

Demographic Sheet 


\section{Personal Information for Study Participants of Research Study: Napping during Shift Work in Nursing Our Lady of Fatima Hospital}

Study Participant Number

Gender: Male $\square \quad$ Female $\square$

Age

Position: $\mathrm{RN} \square$

LPN $\square$

CNA $\square$

Shift: $11 \mathrm{pm}-7 \mathrm{am}$

11pm-7:30am

$7 \mathrm{pm}-7 \mathrm{am}$

7pm-7:30am

Rotating shifts:

Days/nights

Evenings/nights

How many hours per week do you work on this

shift?

How long have you been a nurse/nurse's

aide?

How long have you be employed at St. Joseph's Health Services of

RI?

How long have you worked night shifts since becoming a nurse/nurse's

aide? 
How long have you worked night shifts as an employee of St. Joseph's Health Services of RI?

\section{Medical History}

Have you ever been diagnosed with a sleep disorder? Yes $\square$ No $\square$ If yes, which sleep disorder?

Do you take medication for a sleep disorder on a regular basis? Yes No

Do you smoke? Yes

Do you regularly use caffeine drinks during your shift? Yes $\square$ No $\square$ Sometimes 
Shift Work Napping 72

Appendix E

Fatigue Assessment Scale 


\section{Fatigue Assessment Scale}

Study Participant Number

Nap No Nap/Testing

Beginning of Shift Mid-shift $\quad$ After Nap $\quad$ End of

Shift

The following 10 statements refer to how you feel at the time that you are completing this scale. For each statement you can choose one out of five answer categories varying from never to always. 1 = never; 2 =sometimes; 3 = regularly; 4 = often; and 5 = always

Never Sometimes Regularly Often Always

1. I am bothered by fatigue

1

2

3

4

5

2. I get tired very quickly

1

2

3

4

5

3. I don't do much during the day

1

2

3

4

5

4. I have enough energy for everyday 1

2

3

4

5

5. Physically, I feel exhausted

1

2

3

4

5

6. I have problems starting things

1

2

3

4

5

7. I have problems thinking clearly

1

2

3

4

5

8. I feel no desire to do anything

1

2

3

4

5

9. Mentally, I feel exhausted

1

2

3

4

5

10. When I am doing something, I can concentrate quite well 
Appendix F

Stanford Sleepiness Scale 


\section{Stanford Sleepiness Scale}

Study Participant Number

Nap $\square \quad$ No Nap/Testing

Before shift $\square \quad$ Mid-shift $\square \quad$ After Nap $\square \quad$ End of Shift

\section{An Introspective Measure of Sleepiness}

The Stanford Sleepiness Scale (SSS)

\begin{tabular}{|l|c|}
\hline Degree of Sleepiness & $\begin{array}{c}\text { Scale } \\
\text { Rating }\end{array}$ \\
\hline Feeling active, vital, alert, or wide awake & 1 \\
\hline \begin{tabular}{l|l|}
\hline Functioning at high levels, but not at peak; able to \\
concentrate
\end{tabular} & 2 \\
\hline Awake, but relaxed; responsive but not fully alert & 4 \\
\hline Somewhat foggy, let down & 5 \\
\hline Foggy; losing interest in remaining awake; slowed down & 6 \\
\hline Sleepy, woozy, fighting sleep; prefer to lie down & X \\
\hline $\begin{array}{ll}\text { No longer fighting sleep, sleep onset soon; having dream- } \\
\text { like thoughts }\end{array}$ & \\
\hline Asleep & 7 \\
\hline
\end{tabular}


Appendix $\mathrm{G}$

Reaction Time Testing Results Card 


\begin{tabular}{|c|c|}
\hline \multicolumn{2}{|c|}{ Handheld Reaction Time Testing } \\
\hline Study Participant No. \\
\hline Nap testing $\square$ & \multicolumn{1}{|c|}{ Results in Seconds } \\
\hline Session & \\
\hline 1 & \\
\hline 2 & \\
\hline 3 & \\
\hline 4 & \\
\hline
\end{tabular}

